\title{
A Potential Alternative against Neurodegenerative Diseases: Phytodrugs
}

\section{Jesús Pérez-Hernández, ${ }^{1,2}$ Víctor Javier Zaldívar-Machorro, ${ }^{1,3}$ David Villanueva-Porras, ${ }^{1,4}$ Elisa Vega-Ávila, ${ }^{5}$ and Anahí Chavarría ${ }^{1}$}

\author{
${ }^{1}$ Departamento de Medicina Experimental, Facultad de Medicina, Universidad Nacional Autónoma de México, \\ 06726 México, DF, Mexico \\ ${ }^{2}$ Posgrado en Biología Experimental, Universidad Autónoma Metropolitana-Iztapalapa, 09340 México, DF, Mexico \\ ${ }^{3}$ Programa de Becas Posdoctorales, Universidad Nacional Autónoma de México, 04510 México, DF, Mexico \\ ${ }^{4}$ Posgrado en Ciencias Biomédicas, Universidad Nacional Autónoma de México, 04510 México, DF, Mexico \\ ${ }^{5}$ División de Ciencias Biológicas y de la Salud, Universidad Autónoma Metropolitana, 09340 México, DF, Mexico
}

Correspondence should be addressed to Anahí Chavarría; anahi.chavarria@gmail.com

Received 3 July 2015; Revised 2 November 2015; Accepted 5 November 2015

Academic Editor: Anandh B. P. Velayutham

Copyright (C) 2016 Jesús Pérez-Hernández et al. This is an open access article distributed under the Creative Commons Attribution License, which permits unrestricted use, distribution, and reproduction in any medium, provided the original work is properly cited.

\begin{abstract}
Neurodegenerative diseases (ND) primarily affect the neurons in the human brain secondary to oxidative stress and neuroinflammation. ND are more common and have a disproportionate impact on countries with longer life expectancies and represent the fourth highest source of overall disease burden in the high-income countries. A large majority of the medicinal plant compounds, such as polyphenols, alkaloids, and terpenes, have therapeutic properties. Polyphenols are the most common active compounds in herbs and vegetables consumed by man. The biological bioactivity of polyphenols against neurodegeneration is mainly due to its antioxidant, anti-inflammatory, and antiamyloidogenic effects. Multiple scientific studies support the use of herbal medicine in the treatment of ND; however, relevant aspects are still pending to explore such as metabolic analysis, pharmacokinetics, and brain bioavailability.
\end{abstract}

\section{Introduction}

Neurodegenerative diseases (ND) such as Alzheimer's (AD) and Parkinson's disease (PD) and multiple sclerosis (MS) primarily affect the neurons in the human brain and are characterized by deterioration of neurons or myelin sheath, sensory information transmission disruption, movement control, and more [1]. The greatest risk factor for ND is aging, which carries mitochondrial dysfunction, chronic immuneinflammatory response, and oxidative stress $[2,3]$, the major causes of neuronal damage and death. Nowadays, ND are chronic and incurable conditions whose disabling effects may continue for years or even decades representing an enormous disease load, regarding human suffering and economic cost. The ND are more common and have a disproportionate impact on countries with longer life expectancies and represent the fourth highest source of overall disease burden in the high-income countries. According to the World Health Organization, 37 million people currently have dementia worldwide, and about $50 \%$ of them are being affected by $\mathrm{AD}$ and this number is expected to grow up to 115.4 million people by 2050 [4].

Recently, a great number of natural medicinal plants have been tested for their therapeutic properties, showing that the raw extracts or isolated pure compounds from them have more effective properties than the whole plant as an alternative for the treatment of ND. These properties are due mainly to the presence of polyphenols (Figure 1), alkaloids (Figure 2), and terpenes (Figure 3(d)), among others, that are micronutrients produced by plants as secondary metabolites $[5,6]$. There is substantial evidence (epidemiological studies, animal studies, and human clinical trials) that indicates that polyphenols reduce a wide range of pathologies associated 
<smiles>[R]c1cc(C(=O)O)c([R])c([R])c1[R]</smiles>

(a)<smiles>[R]c1cc(/C=C/C(=O)O)cc([R])c1O</smiles>

(b)<smiles>[R]c1cc(O)ccc1/C=C/c1cc(O)cc(O)c1</smiles>

(c)<smiles>O=C(/C=C/c1ccc(O)c(O)c1)OC1CC(O)(C(=O)O)CC(O)C1O</smiles>

(d)<smiles>CCCCCC(O)CC(=O)CCc1ccc(O)c(OC)c1</smiles>

(e)<smiles>[R]c1cc(CC=C)ccc1O</smiles>

(f)<smiles>COc1ccc(/C=C/C(=O)CC(=O)/C=C/c2ccc(O)c(OC)c2)cc1O</smiles>

(g)<smiles>C=CCc1ccc(O)c(-c2cc(CC=C)ccc2O)c1</smiles>

(h)

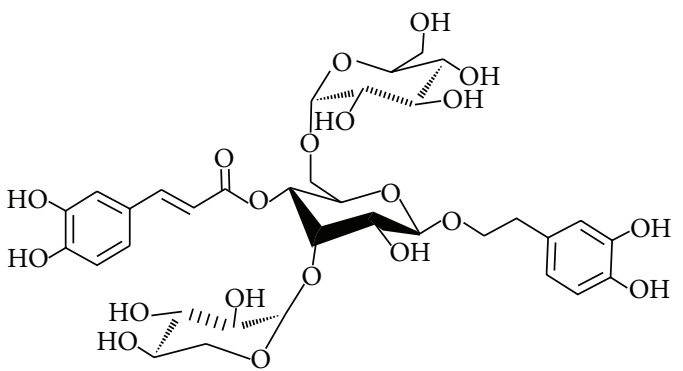

(i)<smiles>COc1ccc(C2CC(OC)c3cc(OC)c(OC)cc3C2OC)cc1OC</smiles>

(j)<smiles>[R]c1ccc(-c2cc(=O)c3c([R3])c([R3])c([R])cc3o2)cc1[R]</smiles>

(k)<smiles>[R]c1ccc(-c2oc3cc([R3])c([R])c([R3])c3c(=O)c2O)cc1[R]</smiles>

(1)<smiles>[R]c1cc([C@H]2Oc3cc(O)cc(O)c3C[C@H]2O)cc(O)c1O</smiles>

(m)<smiles>[R]C1=C([R])C([R3])C2C(=O)CC(c3ccc([R2])c([R])c3)OC2=C1</smiles>

(n)<smiles></smiles>

(o)

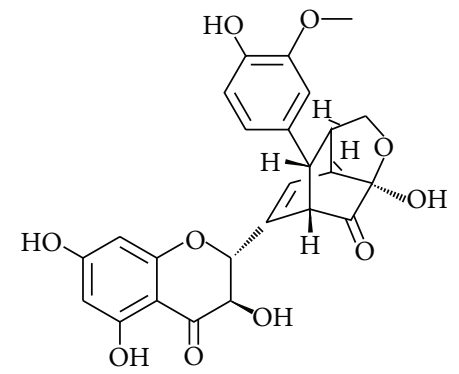

(p)

FIGURE 1: Representative polyphenol compounds. (a) Benzoic acids: $p$-hydroxybenzoic acid $\mathrm{R}_{1}=\mathrm{R}_{3}=\mathrm{R}_{4}=\mathrm{H}, \mathrm{R}_{2}=\mathrm{OH}$; protocatechuic acid $\mathrm{R}_{1}=\mathrm{R}_{4}=\mathrm{H}, \mathrm{R}_{2}=\mathrm{R}_{3}=\mathrm{OH}$; gallic acid $\mathrm{R}_{1}=\mathrm{R}_{2}=\mathrm{R}_{3}=\mathrm{OH}, \mathrm{R}_{4}=\mathrm{H}$; and salicylic acid $\mathrm{R}_{1}=\mathrm{R}_{2}=\mathrm{R}_{3}=\mathrm{H}$, $\mathrm{R}_{4}=\mathrm{OH}$. (b) Hydroxycinnamic acids: coumaric acid $\mathrm{R}_{1}=\mathrm{R}_{2}=\mathrm{H}$; caffeic acid $\mathrm{R}_{1}=\mathrm{OH}, \mathrm{R}_{2}=\mathrm{H}$; ferulic acid $\mathrm{R}_{1}=\mathrm{OMe}, \mathrm{R}_{2}=\mathrm{H}$; and sinapic acid $\mathrm{R}_{1}=\mathrm{R}_{2}=\mathrm{OMe}$. (c) Stilbenes: resveratrol $\mathrm{R}_{1}=\mathrm{H}$; oxyresveratrol $\mathrm{R}_{1}=\mathrm{OH}$. (d) Hydroxycinnamoyl ester: chlorogenic acid. (e) Hydroxycinnamoyl derivatives: gingerol; (f) Chavicol $\mathrm{R}_{1}=\mathrm{H}$; eugenol $\mathrm{R}_{1}=\mathrm{OMe}$; (g) curcumin; (h) magnolol; and (i) echinacoside. Flavonoid compounds. (j) Nobiletin; (k) Flavones: apigenin $\mathrm{R}_{1}=\mathrm{R}_{4}=\mathrm{H}, \mathrm{R}_{2}=\mathrm{R}_{3}=\mathrm{R}_{5}=\mathrm{OH}$; baicalein $\mathrm{R}_{1}=\mathrm{R}_{2}=\mathrm{H}, \mathrm{R}_{3}=\mathrm{R}_{4}=\mathrm{R}_{5}=\mathrm{OH}$; chrysin $\mathrm{R}_{1}=\mathrm{R}_{2}=\mathrm{R}_{4}=\mathrm{H}, \mathrm{R}_{3}=\mathrm{R}_{5}=\mathrm{OH}$; and luteolin $\mathrm{R}_{4}=\mathrm{H}, \mathrm{R}_{1}=\mathrm{OMe}, \mathrm{R}_{2}=\mathrm{R}_{3}=\mathrm{R}_{5}=\mathrm{OH}$. (l) Flavonols: kaempferol $\mathrm{R}_{1}=\mathrm{R}_{4}=\mathrm{H}, \mathrm{R}_{2}=\mathrm{R}_{3}=\mathrm{R}_{5}=\mathrm{OH}$; quercetin $\mathrm{R}_{4}=\mathrm{H}, \mathrm{R}_{1}=\mathrm{R}_{2}=\mathrm{R}_{3}=\mathrm{R}_{5}=$ OH. (m) Flavanols (+)-catechin $\mathrm{R}_{1}=\mathrm{H}$; (+)-gallocatechin $\mathrm{R}_{1}=\mathrm{OH}$. (n) Flavanones: hesperetin $\mathrm{R}_{4}=\mathrm{H}, \mathrm{R}_{1}=\mathrm{R}_{3}=\mathrm{R}_{5}=\mathrm{OH}, \mathrm{R}_{2}=\mathrm{OMe}$; naringenin $\mathrm{R}_{1}=\mathrm{R}_{4}=\mathrm{H}, \mathrm{R}_{2}=\mathrm{R}_{3}=\mathrm{R}_{5}=\mathrm{OH}$; pinocembrin $\mathrm{R}_{1}=\mathrm{R}_{2}=\mathrm{R}_{4}=\mathrm{H}, \mathrm{R}_{3}=\mathrm{R}_{5}=\mathrm{OH}$. (o) Anthocyanins: aurantinidin $\mathrm{R}_{1}=\mathrm{R}_{2}=\mathrm{H}$, $\mathrm{R}_{3}=\mathrm{R}_{4}=\mathrm{OH}$; cyanidin $\mathrm{R}_{2}=\mathrm{R}_{4}=\mathrm{H}, \mathrm{R}_{1}=\mathrm{R}_{3}=\mathrm{OH}$; pelargonidin $\mathrm{R}_{1}=\mathrm{R}_{3}=\mathrm{R}_{4}=\mathrm{H}, \mathrm{R}_{2}=\mathrm{OH}$; and peonidin $\mathrm{R}_{2}=\mathrm{R}_{4}=\mathrm{H}, \mathrm{R}_{1}=\mathrm{OMe}, \mathrm{R}_{3}=$ $\mathrm{OH}$. (p) Flavonolignans: silydianin. 


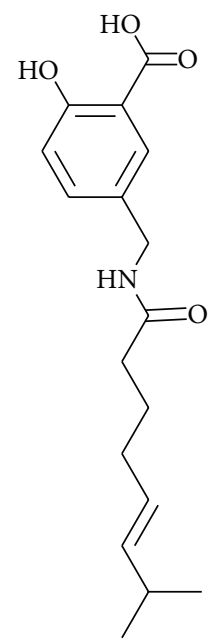

(a)<smiles>[R1]c1cc2c(cc1OC)-c1cc3ccc(OC)c(OC)c3c[n+]1CC2</smiles>

(b)<smiles>CC[C@H]1CCCN2CCc3c2ccccc1n1c3C[C@]1(O)C(=O)OC</smiles>

(c)<smiles>O=C(/C=C/C=C/c1ccc2c(c1)OCO2)N1CCCCC1</smiles>

(d)<smiles>C=CCSSCC=C</smiles>

(e)<smiles>CS(=O)CCCCN=C=S</smiles>

(f)

FIGURE 2: Some alkaloid compounds in plants. (a) Capsaicin; (b) protoberberines: jatrorrhizine $\mathrm{R}_{1}=\mathrm{OH}$, palmatine $\mathrm{R}_{1}=\mathrm{OMe}$; (c) vincamine; (d) piperine; (e) diallyl sulfide; and (f) sulphoraphane.<smiles>CCC1=C(C)C(=O)C(OC)=C(OC)C1=O</smiles>

(a)<smiles>CCNC(=O)CCC(N)C(=O)O</smiles>

(b)<smiles>O=C1OC(C(O)CO)C(O)=C1O</smiles>

(c)<smiles>CC(C)=CCC/C(C)=C/C=C/C(C)=C/C=C/C(C)=C/C=C/C=C(C)/C=C/C=C(C)/C=C/C=C(\C)CCC=C(C)C</smiles>

(d)

FIgURE 3: Some miscellaneous antioxidant compounds from plants. (a) Coenzyme $\mathrm{Q}_{6-10}$; (b) 1-theanine; (c) ascorbic acid; and (d) lycopene.

with inflammation [7-9]. The main mechanisms of polyphenols include their well-characterized antioxidant effects $[10$, 11], inhibition of intracellular kinases activity [12], binding to cell surface receptors [13], and modifying cell membrane functions [14]. Also, recently the neuroprotective effects of polyphenols have been described in several models of ND and involve mainly signaling pathways mediators [15], modulation of enzymes in neurotransmission $[16,17]$, inhibition of neurotoxicity via ionotropic glutamate receptors [18], antiamyloidogenic [19], and anti-inflammatory effects [20]. This review focuses on the plant extracts or compounds isolated from plants that may hold potential in the treatment of the principal ND.

\section{Etiology of Neurodegenerative Diseases}

ND are incurable and disabling conditions secondary to progressive neuronal loss, which leads to chronic brain damage and neurodegeneration. The etiology of ND is still unknown, although several ND animal models showed associated damage with the blood-brain barrier, protein aggregation, toxin exposure, and mitochondrial dysfunction, which lead to oxidative stress and inflammation, and consequently neuronal death [21].

The blood-brain barrier controls the internal environment of the vertebrate CNS and represents the border between the capillary and the extracellular fluid of CNS neurons and glial cells; it also ensures specific brain homeostasis 
allowing adequate neuronal function [22]. Neurovascular changes normally occur as part of aging, but these are more evident in chronic ND [23]. About 20\% of blood flow decreases in the aged brain, which associates with reduced protein synthesis [24]. Interestingly, this blood flow reduction is higher in the presence of any ND, which may lead to changes in intracellular $\mathrm{pH}$ and accumulation of interstitial lactate and glutamate $[23,25]$. These changes are observed in specific brain regions in diseases such as $\mathrm{AD}, \mathrm{PD}, \mathrm{MS}$ among other CNS disorders [25-28].

Abnormal protein aggregation of specific regions and neuronal populations is a common feature among ND. For example, the $\alpha$-synuclein inclusions in dopaminergic neurons from the substantia nigra are the main histopathological marker in PD [29]. Also, insoluble aggregates of the amyloid beta-peptide $(\mathrm{A} \beta)$ and neurofibrils composed of Tau protein are found in $\mathrm{AD}[30,31]$ and hyperphosphorylated Tau aggregation in demyelination areas in MS [32]. Finally, superoxide dismutase 1 (SOD1) aggregations are present in amyotrophic lateral sclerosis (ALS) [33]. The main relevance of protein aggregates is that they lead to mitochondrial dysfunction inducing apoptotic neuronal death.

Redox state imbalance and chronic inflammation, a major cause of cell damage and death, characterize ND [34]. Reactive oxygen species (ROS) are key mediators of cell survival, proliferation, differentiation, and apoptosis $[35,36]$. Excessive production of ROS by mitochondria and NADPH oxidase in oxidative stress is usually thought to be responsible for tissue damage associated with inflammation and ND [34, 36-38]. Moreover, many of the well-known inflammatory target proteins, including matrix metalloproteinase-9, cytosolic phospholipase $\mathrm{A}_{2}$, cyclooxygenase-2, inducible nitric oxide synthase (iNOS), and adhesion molecules, are associated with oxidative stress and induced by proinflammatory factors such as cytokines, peptides, and peroxidants agents [36, 39, 40]. Several studies have shown that ROS act as a critical signaling molecule to trigger inflammatory responses in CNS through the activation of the redox-sensitive transcription factors, including nuclear factor $-\kappa \mathrm{B}(\mathrm{NF}-\kappa \mathrm{B})$ and activator protein-1 [34, 36-39].

Mitochondrial damage leads to neuronal oxidative damage in ND pathogenesis. ROS and reactive nitrogen species, which are normal byproducts of mitochondrial respiratory chain activity, are mediated by mitochondrial antioxidants such as manganese superoxide dismutase and glutathione peroxidase. In addition to the ROS generation, mitochondria are also involved with life-sustaining functions including adenosine triphosphate synthesis by oxidative phosphorylation, apoptosis, calcium homeostasis, mitochondrial fission and fusion, lipid concentration of the mitochondrial membranes, and the mitochondrial permeability transition. Mitochondrial disease leading to neurodegeneration is likely, at least on some level, to involve all of these functions [41]. In ND several mitochondrial alterations are found like bioenergetics anomalies in the process of oxidative phosphorylation and ATP production, defects of mitochondrial dynamics, increase sensitivity to apoptosis, and accumulation of damaged mitochondria with unstable mitochondrial DNA [2].
The proteins aggregation also plays an important role in mitochondrial dysfunction; for example, the accumulation of mitochondrial $\mathrm{A} \beta$ aggregates has been observed both in patients and in transgenic models of AD [42-44]. Additionally, inhibition of mitochondrial complex I occurs in $\mathrm{PD}$ patients [45] and the two principal models used for the study of PD. Rotenone-a natural compound used as an insecticide, piscicide, and pesticide-and 1-methyl4-phenyl-1,2,3,6-tetrahydropyridine (MPTP) - a neurotoxin precursor of 1-methyl-4-phenylpyridinium $\left(\mathrm{MPP}^{+}\right)$, which destroys dopaminergic neurons in the substantia nigraboth act by inhibiting mitochondrial complex I [21]. In ALS, mitochondrial SOD1 enzyme aggregates cause loss of mitochondrial function and induce cellular death by apoptosis [46]. This phenomenon is present in almost all ND and associated with inflammation, which is one of the points of therapeutic interest and study.

The CNS inflammation is dependent on inflammatory mediators produced mainly by glial cells, specifically microglia and CNS macrophages [47]. Microglial activation is crucial in the pathogenesis and the course of $\mathrm{PD}$ [48], AD [49], prion disease [50], and MS [51], among others. Uncontrolled microglia activation produces neuronal damage due to overproduction of proinflammatory mediators such as tumor necrosis factor $\alpha(\mathrm{TNF} \alpha)$ [52], and nitric oxide (NO), leading to the generation of oxidative stress and apoptotic cell death $[48,52,53]$.

\section{Main Therapeutic Effects of Plant Extracts}

The plant extracts have become interesting candidates as therapeutic agents due to their antioxidant, anti-inflammatory properties, and chemical characteristics derived as follows.

(i) Direct Uptake of Free Radicals. Primarily polyphenols (Figure 1) and alkaloids (Figure 2) function as scavengers due to their multiple phenolic hydroxyl and nitrogen groups, respectively, which act as an electron donor to the aromatic ring. These systems are excellent nucleophiles that readily lose electrons and easily oxidize. Therefore, they can catch free radicals and react with ROS, such as superoxide, peroxyl, hydroxyl radicals, NO, nitrogen dioxide, peroxynitrite, and singlet oxygen [54-56].

(ii) Chelation of the Divalent Cations in Fenton Reactions Involved. Many polyphenol compounds chelate iron cations due to multiple hydrophilic groups and are efficient scavengers because phenolic groups inhibit iron-mediated oxyradical formation like other iron chelators, such as desferrioxamine, 1,10-phenanthroline, and pyridoxal isonicotinoyl hydrazone $[57,58]$.

(iii) Modulation of Enzymes Associated with Oxidative Stress. ND associate with molecular alterations in cell-signaling pathways that regulate cell proliferation and differentiation, such as the family of mitogen-activated protein kinases (MAPK). Abnormal activation or silencing of the MAPK pathway or its downstream transcription factors can result 
in uncontrolled cell growth leading to malignant transformation. Some plant compounds "switch on" or "turn off" the specific signaling molecule(s), depending on the nature of the signaling cascade they target, preventing abnormal cell proliferation and growth $[59,60]$.

\section{Antioxidant and Anti-Inflammatory Properties in Central Nervous System}

Flavonoids, a type of polyphenolic compounds found in fruits, vegetables, red wine, and green tea, reduce the risk to developing ND [61]. In 2010, Vuong and colleagues showed that cranberry juice in neuronal cultures significantly increased the activity of antioxidant enzymes such as catalase and SOD1 and protected neurons against $\mathrm{H}_{2} \mathrm{O}_{2}$ induced cell death, possibly due to the activation of survival pathways dependent from p38 and blocking death pathway associated with MEK1/2 and ERK1/2 [62]. A comparative study of two extracts of Salvia species, S. hydrangea and $S$. macilenta, also showed strong antioxidant properties, also at high concentrations $(\geq 50 \mu \mathrm{g} / \mathrm{mL})$ they can inhibit DNA damage by free radicals. Moreover, these species not only showed no cytotoxic effect in cultured PC12 cells, a cell line derived from a pheochromocytoma obtained from rat adrenal medulla differentiated with neural growth factor, but also protected them from peroxide-induced cell death [63]. Similarly selaginellin, a compound extracted from the plant Saussurea pulvinata, showed a neuroprotective effect in a glutamate neurotoxicity model in PC12 cells by trapping ROS and regulating the expression of the klotho gene, which has an antiapoptotic role [64].

Ginger, the root of Zingiber officinale, an important specie used in the Chinese, Ayurvedic, and Tibia-Unani traditional medicine, has anti-inflammatory [65-67] and antioxidant [68] properties, among others. The hexane fraction of ginger extract and the methanol extract of Ficus religiosa sheet significantly decreased the production of $\mathrm{NO}$, prostaglandin E2, IL-1 $\beta$, IL-6, and TNF $\alpha$ through the inhibition of MAPK and NF- $\kappa$ B in BV2 microglial cell line stimulated with lipopolysaccharide (LPS) [69, 70].

Similarly, the ethanol extract of Knema laurina exerted anti-inflammatory and neuroprotective effects in a BV2 microglial cell culture line, in HT-22 hippocampal neurons and in organotypic hippocampal cultures. Knema laurina reduced microglial production of NO and IL- 6 through the inhibition of ERK1/2 and IKK $\beta$ phosphorylation, and the subsequent translocation NF- $\kappa \beta$ in microglial cells [71].

\section{Therapeutic Opportunities for Plant Extracts in Central Nervous System Age-Related Changes}

It is clear that aging is a critical factor for developing ND and facilitates the microglial promoted proinflammatory environment [72-74] and oxidative stress [75]. Therefore, studying potential drugs that prevent or retard age-related changes has become crucial. Natural antioxidants such as some cocoa derivatives have shown to contain higher flavonoids levels [76]. For example, acticoa, a cocoa-derived polyphenol extract, administered daily orally at $24 \mathrm{mg} / \mathrm{kg}$ dose in Wistar rats 15 to 27 months old, improved cognitive performance, increased life expectancy, and preserved free dopamine levels in urine [77]. Another extract with high antioxidant activity is silymarin, a standardized mixture of flavonolignans (Figure 1(p)) extracted from the Silybum marianum fruits and seeds [78]. The treatment with $400 \mathrm{mg} / \mathrm{kg} / \mathrm{day}$ of silymarin during three days increased reduced glutathione (GSH) and SOD activity in the brain of aged rats [79]. Vincamine (Figure 2(c)), a monoterpenoid indole alkaloid purified from the Vinca minor plant, has antioxidant activity similar to vitamin E. This compound increased cerebral blood flow, glucose, and oxygen utilization in neural tissue and promoted the rise of dopamine, serotonin, and noradrenaline levels [80]. Also, the treatment of rats with vincamine during 14 days at a daily dose of $15 \mathrm{mg} / \mathrm{kg}$ reduced about $50 \%$ the brain iron levels, which suggests a beneficial effect in reducing the oxidative stress associated with the iron deposition in ND [81]. Moreover, paeonol, a compound extracted from the Paeonia suffruticosa cortex or Paeonia lactiflora root, has been ascribed to anti-inflammatory and antioxidant properties. Paeonol effects were tested in a model of neurotoxicity induced with D-galactose injected subcutaneously in aged mice. Paeonol prevented memory loss in this model since it increased acetylcholine and GSH levels and decreased the activity of acetylcholinesterase (AChE) and SOD1 in the hippocampus and cortex, positioning it as a potential drug useful in age-related ND [15]. Also, Magnolia officinalis compounds, magnolol (Figure 1(h)) and their isomer honokiol, were tested in a senescence-accelerated prone mice; this compound prevented learning and memory deterioration, as well as acetylcholine deficiency by preserving forebrain cholinergic neurons [18, 82].

\section{Plant Compounds Used for Alzheimer's Disease}

$\mathrm{AD}$ manifests as a progressive cognitive and behavioral disorder and is characterized by an immediate loss of memory secondary to neuronal loss in the limbic and association cortices. This neuronal death results from oxidative stress, neuroinflammation, and abnormal protein deposition [83], leading to a therapeutic opportunity for medicinal plants, which improve $\mathrm{AD}$ course principally by modulating $\mathrm{A}$ aggregation, AChE activity, oxidative stress, and inflammatory response [84].

Cryptotanshinone is an active component of Salvia miltiorrhiza with anti-inflammatory, antioxidant, and antiapoptotic properties $[85,86]$. This compound crossed the blood brain barrier and decreased cognitive deficits in male IRC mice with scopolamine-induced cognitive impairments [87]. This compound also provided beneficial effects in patients with ischemia and cerebral infarct [88]. Additionally, cryptotanshinone reduced the $\mathrm{A} \beta$ aggregation in brain tissue and improved spatial learning and memory in APP/PS1 transgenic mice by promoting amyloid precursor protein metabolism via $\alpha$-secretase pathway [89]. Silymarin also showed antiamyloid properties in vitro, and its chronic 
administration (half a year) significantly reduced the $\mathrm{A} \beta$ plaque burden associated with microglial activation, $A \beta$ oligomer formation, and hyperactivity and disturbed behavior in APP transgenic mice [90]. The protective effect of silymarin on $A \beta$ accumulation is attributable to the blockade of its aggregation, not to $\beta$-secretase inhibition [89]. The use of Centella asiatica in a dementia model in PSAPP mice improved memory retention in rodents $[91,92]$ and decreased amyloid deposition and the spontaneously $\mathrm{A} \beta$ plaque formation [93]. Likewise, the grape seed polyphenolic extract from Vitis vinifera attenuated the cognitive impairment observed in aging $\mathrm{AD}$ transgenic mice and decreased $\mathrm{A} \beta$ plaques deposition in the brains [94]. Nobiletin (Figure 1(j)), a flavonoid purified from Citrus depressa plant, prevents memory loss in APP695 transgenic mice and A $\beta$ treated rats. This compound reduces the $\mathrm{A} \beta$ plaques amount in the hippocampus $[95,96]$, probably by reducing the inhibition of protein kinase A and cAMP response element-binding protein phosphorylation signaling cascade [97]. Nobiletin also stimulated long-term potentiation in organotypic hippocampal cultures [98]. Other compounds that can prevent $\mathrm{A} \beta$ aggregation by inhibition of the metabolic pathway that generates $\mathrm{A} \beta$ plaques are berberine, palmatine, jateorrhizine, epiberberine, coptisine, groenlandicine, and magnoflorine, alkaloids isolated from Coptis chinensis rhizome [99]. These compounds also exhibit AChE inhibiting properties $[100,101]$ and antidepressant effects [59] and enhance cognitive improvements [102]. Also, jateorrhizine (Figure 2(b)) and groenlandicine have significant peroxynitrite scavenging activities, while coptisine and groenlandicine present moderate total ROS inhibitory activities [99].

The ethanol extract from Cassia obtusifolia has potential use in $\mathrm{AD}$, which reduced scopolamine-induced memory loss in mice by inhibiting AChE [103]. Similarly, methoxsalen, the main component of the aqueous extract of Poncirus trifoliata, inhibited AChE activity reducing memory loss and learning problems associated with a neurotoxicity in vivo model induced with trimethyltin [16]. In the AD model induced with ethylcholine aziridinium, which mimics the cholinergic hypofunction present in AD [104], piperine (Figure 2(d)), an alkaloid present in Piper longum, lowered the cognitive deficits and the hippocampal neurodegeneration associated with this AD model [105]. These effects could be probable due to its anti-inflammatory [106] and antioxidant activities [71].

The treatment for 5 weeks with L-theanine (Figure 3(b)), an amino acid present in green tea Camellia sinensis, significantly decreased memory loss associated with intraventricular $\mathrm{A} \beta_{1-42} \mathrm{AD}$ model. L-theanine as well reduced cortical and hippocampal neuronal death, also inhibited lipid peroxidation and protein damage, and increased GSH levels, suggesting its potential use in AD prevention and treatment [17]. Also, Dioscorea opposita chloroform extract, which has been used to treat memory-related diseases such as $\mathrm{AD}$ and others ND, prevented neuronal death, and significantly increased spatial learning and memory improvement, probably due to its antiexcitotoxic and antioxidant effects [107].

Sanmjuanhwan (Sjh), a multiherbal formula from oriental traditional medicine, composed of Morus alba, Lycium chinense, and Atractylodes japonica, showed neuroprotective effects on primary neuronal cultures exposed to $\mathrm{A} \beta_{25-35}$. Sjh increased the expression of antiapoptotic proteins such as Bcl-2 and avoided cytochrome $c$ release and caspase- 3 activation [108]. B. monnieri and its active components bacoside A, bacopaside I and II, and bacosaponin C $[109,110]$ have anti-inflammatory, antimicrobial, and antidepressant effects [111-113]. Treatment with B. monnieri prevented neuronal death by the inhibition of AChE activity in primary cortical culture pretreated with $\mathrm{A} \beta_{25-35}$ [114]. Furthermore, animals and volunteers treated with this plant presented enhanced memory [115-117]. The antioxidant effect of $S$-allyl cysteine (SAC), an amino acid isolated from aged garlic, was tested in the $\mathrm{A} \beta_{25-35}-\mathrm{AD}$ rat model, showing ROS scavenger activity in vivo [118]. Also, in the mice AD dementia model induced with the intracerebroventricular streptozotocin infusion, SAC pretreatment decreased $\mathrm{p} 53$ expression, restored $\mathrm{Bcl}-2$ protein expression, reduced, and prevented DNA fragmentation [119].

Mono- and diacetyled cyanidin and peonidin, the purple sweet potato anthocyanins (PSPA; Figure 1(o)) extracted from Ipomoea batatas, can easily attract ROS, which has high clinical value as antioxidant therapy in $\mathrm{AD}$ and other ND $[120,121]$. For example, pretreatment of PC12 cells with PSPA reduced $\mathrm{A} \beta$ toxicity preventing lipid peroxidation, caspase- 3 activation, and $\mathrm{A} \beta$-induced apoptosis, suggesting a possible use in the treatment of $\mathrm{AD}$ [122].

Finally, the use of ginseng, Panax ginseng, was evaluated in $\mathrm{AD}$ patients, those who received a daily dose $9 \mathrm{~g}$ of Korean red ginseng for 12 weeks showed a significant improvement in the $\mathrm{AD}$ assessment scale and the clinical dementia rating scale compared to control patients [123].

\section{Plant Compounds for Parkinson's Disease Treatment}

$\mathrm{PD}$ is the second most frequent $\mathrm{ND}$ and is primarily a movement disorder characterized by the loss of dopamineproducing neurons in substantia nigra. Activation of neuronal death pathways involves oxidative stress, neuroinflammation, and mitochondrial dysfunction [124].

Green tea extract and its isolated (-)-epigallocatechin-3gallate polyphenol, as well as ginseng extract, have neuroprotective effects since their use diminished dopaminergic neuron loss in the substantia nigra and oxidative damage in an MPTP and its toxic metabolite $\mathrm{MPP}^{+}$in PD animal models $[125,126]$. Also, Chrysanthemum morifolium, which has antioxidant activity [126], inhibited MPTP-induced cytotoxicity and maintained cell viability of SH-SY5Y cell line, preventing ROS formation, decreasing $\mathrm{Bax} / \mathrm{Bcl} 2$ ratio and caspase- 3 activation [127]. The administration of $20 \mathrm{mg} / \mathrm{kg}$ of echinoside, a compound isolated from Cistanche salsa, before MPTP intoxication maintained striatal dopamine levels, reduced cell death, significantly increased the tyrosine hydroxylase enzyme expression, and reduced the activation of caspase- 3 and caspase- 8 expression, thus preventing neuronal death [128]. Likewise, silymarin treatment preserved dopamine levels, diminished the number of apoptotic cells, and preserved dopaminergic neurons in the substantia nigra of MPTP- and 6-hydroxydopamine-intoxicated mice 
(6-OHDA) [74, 129-131]. Besides, pelargonidin (Figure 1(o)), an anthocyanidin with neuroprotective effects, reduced the motor deficit and histological damage and prevented lipid peroxidation in the 6-OHDA model [132-134].

In the MPTP-intoxicated model of PD, SAC prevented lipid peroxidation and mitochondrial dysfunction [135], protected the striatum of mice from the morphological alterations with a reduction in TNF- $\alpha$ and iNOS expressions, and further reduction in astrocyte activation [136] and also, at $120 \mathrm{mg} / \mathrm{kg}$ dose by five days, partially ameliorated the MPTPinduced striatal and nigral dopamine and tyrosine hydroxylase depletion, attenuated the loss of manganese-dependent superoxide dismutase and heme oxygenase-1 activities, and preserved the protein content of these enzymes [137]. These findings suggest that SAC can exert neuroprotection since the origin of the dopaminergic lesion-at the substantia nigra-not only by using direct antioxidant actions but also through Nrf2 nuclear transactivation and phase 2 enzymes upregulation [137].

The commercial extract of Anemopaegma mirandum, a Brazilian tree, and the crude extract of Valeriana officinalis increased the viability of SH-SY5Y cells after rotenone exposure $[138,139]$, while the extract of Rhus verniciflua decreased ROS production, preserved the mitochondrial integrity, and decreased the number of apoptotic cells [140]. An extract from Tripterygium regelii, a plant with antioxidant properties, reduced oxidative stress-induced cell death through the inhibition of apoptotic cascades, preserved mitochondrial function, and promoted tyrosine hydroxylase expression and brain-derived neurotrophic factor (BDNF) production in $\mathrm{H}_{2} \mathrm{O}_{2}$ treated SH-SY5Y cells [141]. Also, in the MPP ${ }^{+}$ intoxicated SH-SY5Y cells, the orchid increased cell viability, decreased cytotoxicity and ROS production, and prevented caspase- 3 activation by diminishing the $\mathrm{Bax} / \mathrm{Bcl} 2$ ratio [142].

In the same model, the flavonoid luteolin (Figure 1(k)) a compound present in celery, green pepper, pear leaves, and chamomile tea-provided neuroprotection against oxidative stress [143]. Also, luteolin inhibited LPS induced microglial activation, as well as the production of TNF $\alpha, \mathrm{NO}$, and superoxide in a midbrain mixed primary cultures [144]. Pedicularoside A, a glycosylated phenylethanoid isolated from Buddleja lindleyana, has anti-inflammatory properties and is a good scavenger of superoxide anions and hydroxyl radicals [145]; it protected against $\mathrm{MPP}^{+}$-induced death in mixed midbrain primary culture by increasing tyrosine hydroxylase expression and decreasing caspase-3 cleavage [146]. The plant extract from Uncaria rhynchophylla decreased cell death and ROS production and increased GSH levels in cultured PC12 cells, while 6-OHDA-induced caspase- 3 activation was attenuated preventing cell death and rotational behavior was significantly reduced in the 6-OHDA PD model [147]. The ethyl extract from Myracrodruon urundeuva displayed similar properties in mesencephalic cultured cells since it preserved cell viability and attenuated oxidative stress after 6-OHDA exposure [148].

Panax notoginseng (PN) has the property to increase the expression of certain molecules such as nestin and BDNF, promoting neural plasticity and recovery after cerebral ischemia $[149,150]$. Also, PN induces the expression of thioredoxin-1, an oxidoreductase with antiapoptotic and cell growth promoter effects [151], reducing MPTP-induced cell death in PC12 cells [152]. Likewise, the root extract of Withania somnifera promoted axon and dendrite growth $[153,154]$ and also increased the levels of SOD1, catalase, and GSH, preventing deficit motor in MPTP-intoxicated animals [155].

The isoflavones daidzin, daidzein, and genistein contained in Pueraria thomsonii protected PC12 cells stimulated with 6-OHDA through the inhibition of the caspase3 activation [156]. Moreover, genistein, a soy phytoestrogen, protected neurons from substantia nigra pars compact and attenuated the rotational behavior in a hemiparkinsonian 6-OHDA model [157]. Interestingly, the administration of Mucuna pruriens preceding 6-OHDA intoxication was more efficient than levodopa in controlling motor symptoms, since it restored dopamine and norepinephrine levels in the nigrostriatal track exhibiting a neuroprotective effect [158]. The mechanism of action of Mucuna pruriens is not fully understood; however, it has been proposed that increases the mitochondrial complex I activity without affecting the monoamine oxidase $\mathrm{B}$ activity, probably due to its high content of NADH and Q-10 coenzyme (Figure 3(a)), and its ability to scavenge ROS [159].

The herbal mixture Toki To (TKT), prepared of ten different plants (Angelicae Radix, Pinelliae Tuber, Cinnamomi Cortex, Ginseng Radix, Magnoliae Cortex, Paeoniae Radix, Astragali Radix, Zanthoxyli fructus, Zingiberis siccatum Rhizoma, and Glycyrrhizae Radix), has excellent results against PD [159]. TKT orally administered reduced motor symptoms such as bradykinesia, prevented dopaminergic neurons loss in the substantia nigra, and increased tyrosine hydroxylase and dopamine transporter expression in MPTP-intoxicated mice [159]. Through microarray it was determined that TKT per se regulates the expression of serum- and glucocorticoid regulated kinase gene $(s g k)$, which are implicated in the PD pathogenesis [159].

Psoralea corylifolia seeds, specifically $\Delta 3,2$-hydroxybakuchiol monoterpene, which has been used for years in Chinese medicine for the treatment of cerebral aging and dementia $[102,160]$, protected SK-N-SH cells from MPP ${ }^{+}$intoxication and prevented the dopaminergic neurons loss in MPTPintoxicated mice by inhibition of the monoamine transporter $[161,162]$. Also it is worth mentioning that Rosmarinus officinalis, a plant used as flavoring in Mediterranean cuisine, has antioxidant properties [163]. Rosmarinus officinalis inhibits NO production [164] and protects dopaminergic neurons in different degenerative disease models [165-168], probably due to its a high content of polyphenols and terpenes such as carnosol, carnosic acid, and rosmarinic acid and antiapoptotic effects [169].

\section{Plant Compounds for Cerebral Ischemia Management}

In cerebral ischemia, severe neuronal damage occurs during the reperfusion period due to excitotoxicity, which consists of 


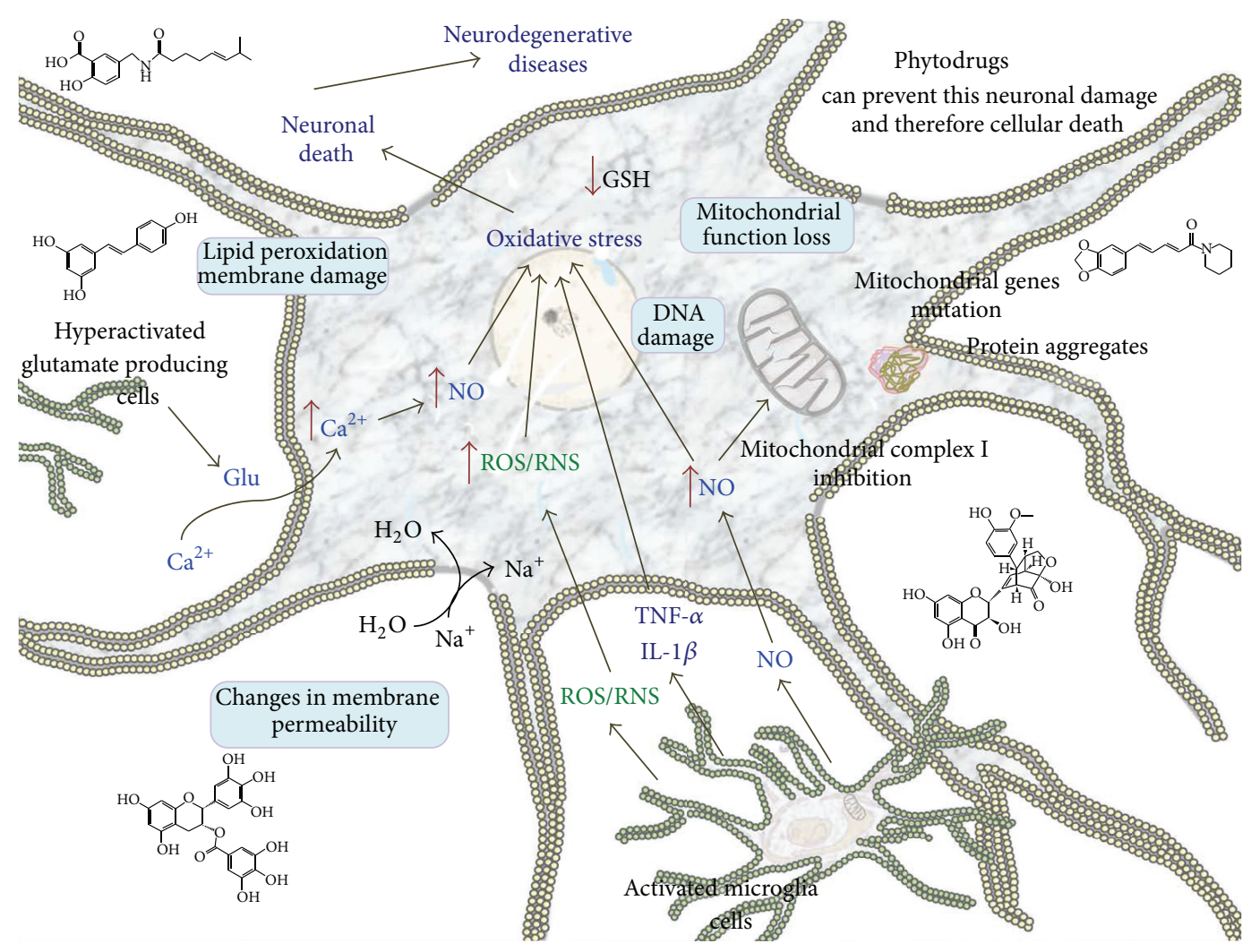

FIGURE 4: Main neuronal death pathways caused by oxidative stress. Oxidative stress can lead to neuronal death via several mechanisms such as mitochondrial dysfunction, DNA damage, membrane permeability loss, protein aggregation, and apoptosis. Phytodrugs, mainly polyphenols and alkaloids, can prevent this neuronal damage and, therefore, cellular death. Thus, these natural compounds can be used in the treatment of ND and also could serve as models for developing new specific drugs against these pathologies.

an overstimulation of $N$-methyl-D-aspartate (NMDA) receptors leading to glutamate production, which in turn triggers oxidative and inflammatory processes [26]. The intraperitoneal administration of $200 \mathrm{mg} / \mathrm{kg}$ of cactus polysaccharides, the active component isolated from Opuntia dillenii, prior to the middle cerebral artery occlusion showed neuroprotective effects $[170,171]$. Opuntia dillenii significantly reduced infarct volume, decreased neuronal loss in the cerebral cortex, and diminished importantly the nitric oxide synthase (NOS) synthesis, which is usually induced during the experimental period of reperfusion and ischemia [171]. Also, oral pretreatment with 30 and $50 \mathrm{mg} / \mathrm{kg}$ daily of Smilacis chinae rhizome (SCR) methanol extract reduced the histological changes associated with ischemic injury [172]. It is possible that SCR prevented excitotoxicity-induced neuronal death by decreasing ROS generation, similar to the observations made in vitro in primary cultures of cortical cells treated with $1 \mathrm{mM}$ NMDA [172]. Additionally, intravenous pretreatment with silymarin reduced infarcted area size, as well as neurological deficits associated with ischemic damage [173]. Also, silymarin inhibited protein expression associated with inflammation such as iNOS, cyclooxygenase2 , myeloperoxidase, the nuclear transcription factor NF$\kappa \mathrm{B}$, and proinflammatory cytokines like IL- $1 \beta$ and TNF $\alpha$, avoiding neurodegeneration associated with ischemia [173].
Similarly, SAC administration reduced infarct volume in a rat brain ischemia model [174] and decreased lipid peroxidation to basal levels suggesting SAC beneficial effects in brain ischemia and that the major protective mechanism may be the inhibition of free radical-mediated lipid peroxidation [175].

\section{Conclusions}

Neurodegenerative diseases (ND) are chronic and progressive conditions, characterized by neuronal loss secondary to oxidative stress and neuroinflammation (Figure 4). Until now ND have no cure and represent high costs for the health system and patients families. Exploring alternative sources for ND therapy has led to set eyes on herbal medicine since most herbal compounds have antioxidant and antiinflammatory properties. At present, the use of several plants in the treatment of ND is being supported by numerous scientific investigations (the main effects of herbal plants against ND are listed in Table 1). However, information is still missing on relevant aspects such as metabolism, pharmacokinetics, and bioavailability in the brain as well as any changes that they may have in the CNS. Nevertheless, plant compounds or extracts remain interesting therapeutic candidates for ND management. 


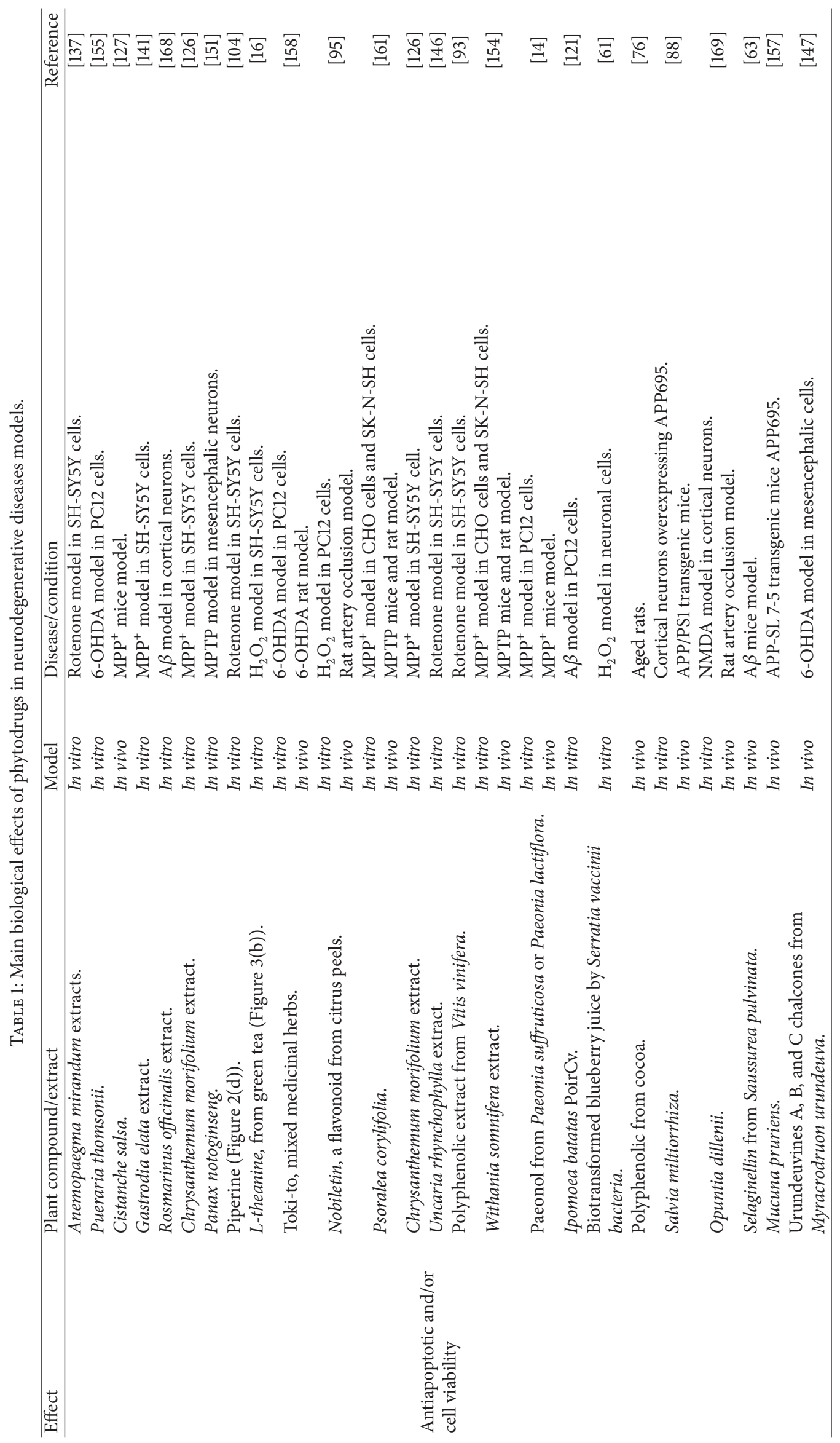




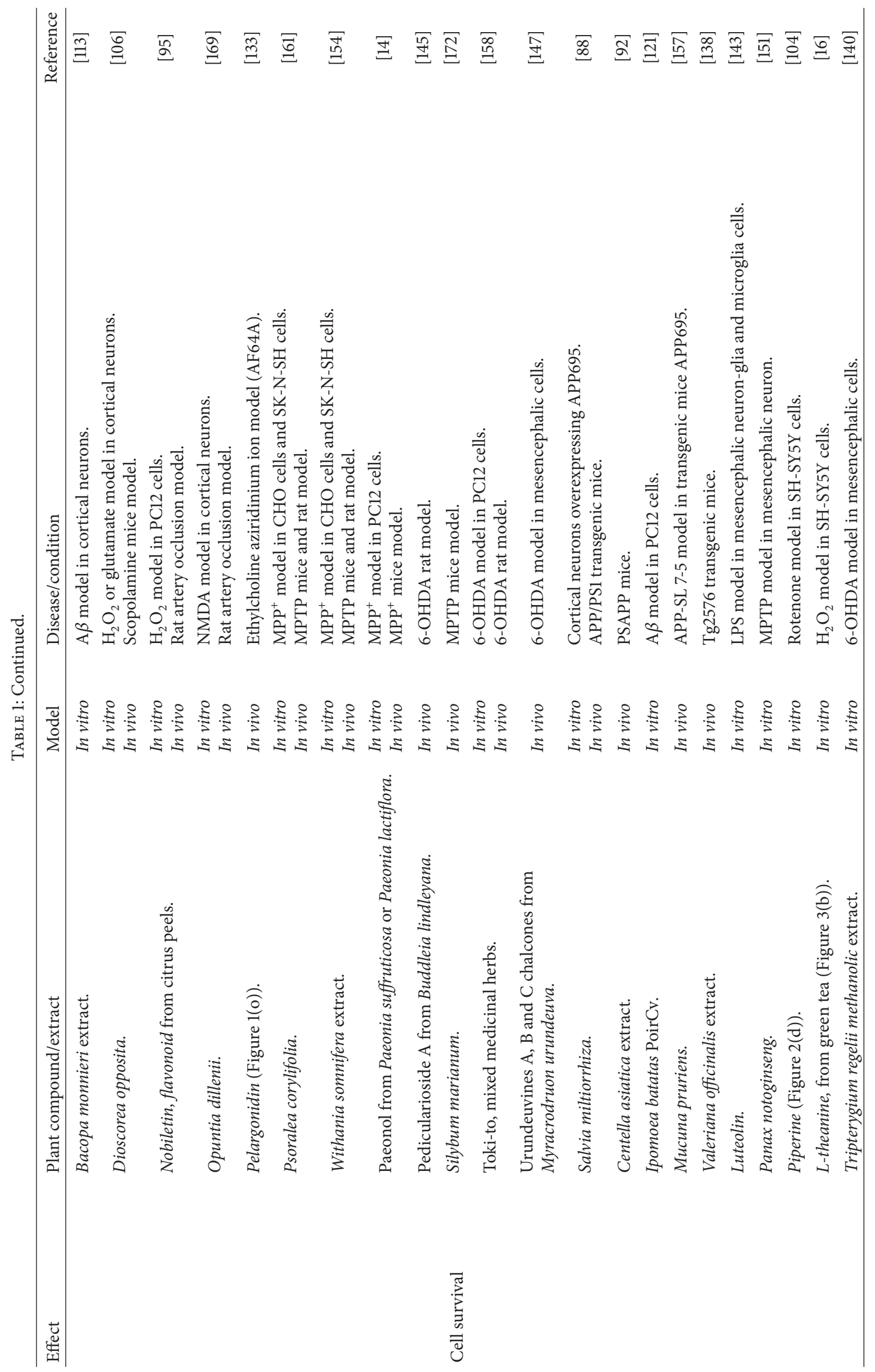




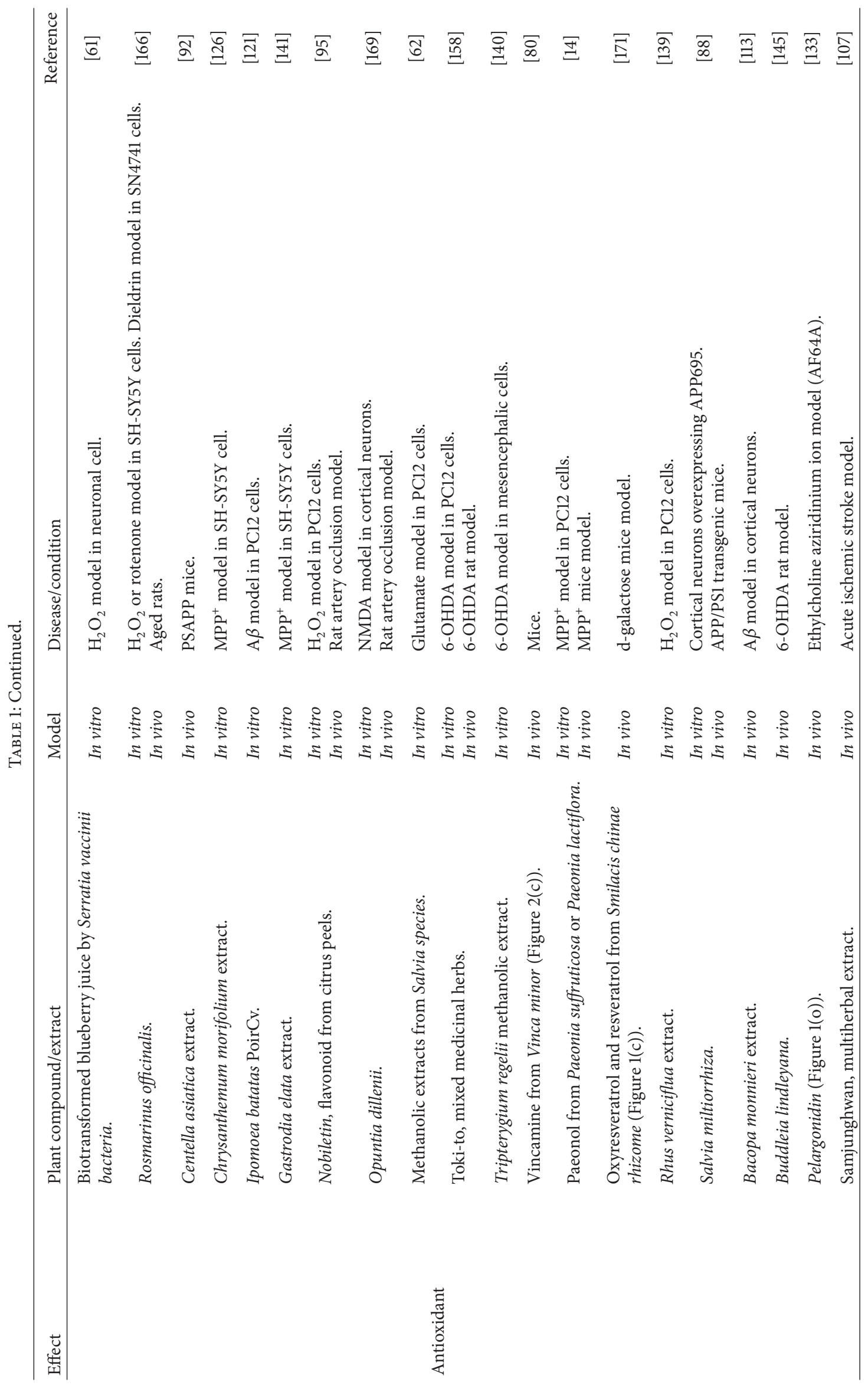




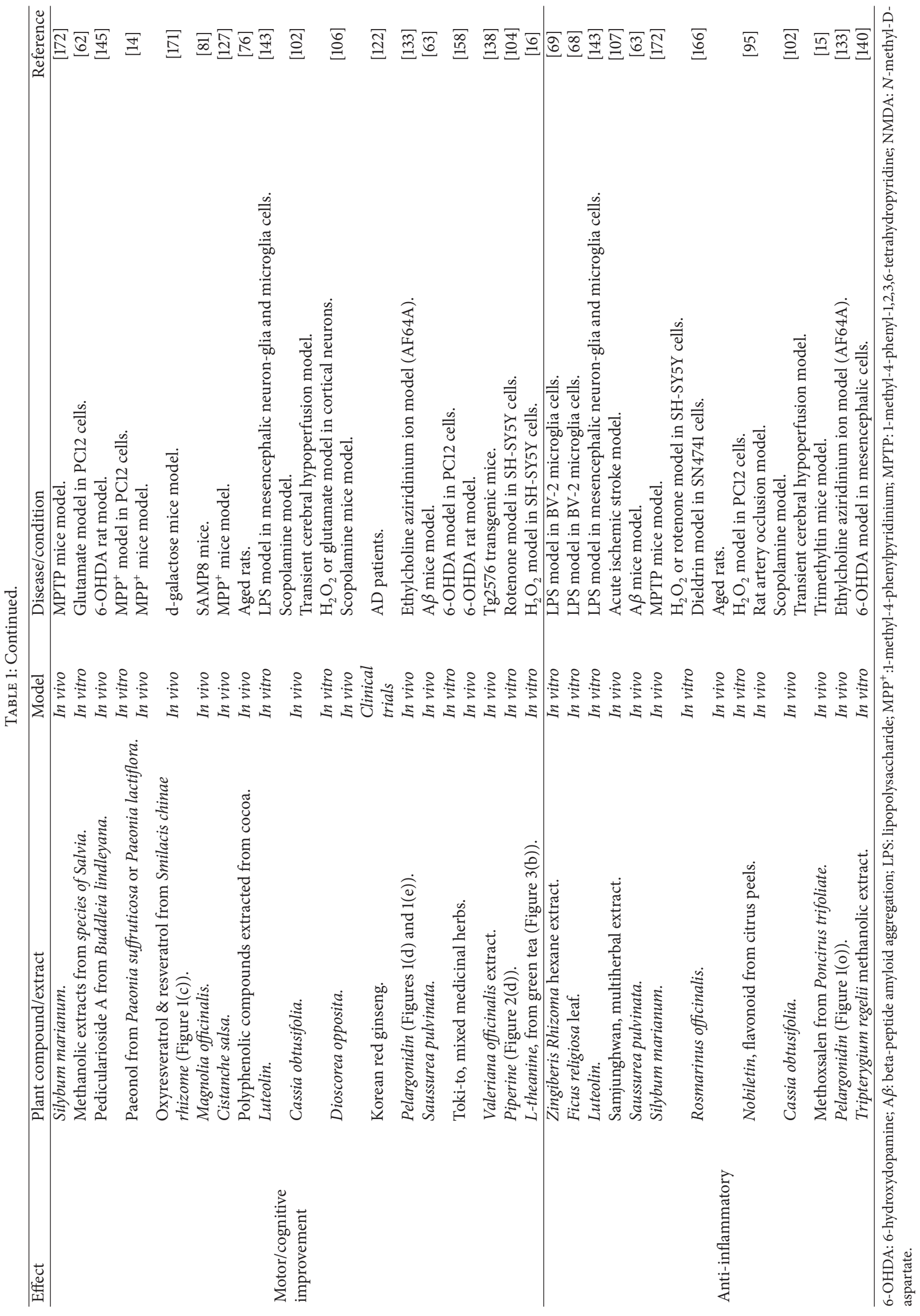




\section{Abbreviations}

\begin{tabular}{|c|c|}
\hline AChE: & Acetyl cholinesterase \\
\hline AD: & Alzheimer's disease \\
\hline $\mathrm{A} \beta:$ & Amyloid beta-peptide \\
\hline ALS: & Amyotrophic lateral sclerosis \\
\hline Bax: & Apoptosis regulator \\
\hline Bcl-2: & $\begin{array}{l}\text { B cell lymphoma 2; family of regulator } \\
\text { proteins of apoptosis }\end{array}$ \\
\hline BDNF: & Brain-derived neurotrophic factor \\
\hline CNS: & Central nervous system \\
\hline CAMP: & Cyclic adenosine monophosphate \\
\hline DNA: & Deoxyribonucleic acid \\
\hline ERK: & Extracellular signal-regulated kinase \\
\hline GSH: & Glutathione reduced \\
\hline $\mathrm{H}_{2} \mathrm{O}_{2}$ : & Hydrogen peroxide \\
\hline IL-1 $\beta$ : & Interleukin $1 \beta$ \\
\hline IL-6: & Interleukin 6 \\
\hline iNOS: & Inducible nitric oxide synthase \\
\hline LPS: & Lipopolysaccharide \\
\hline MAPK: & Mitogen-activated protein kinase \\
\hline MEK: & $\begin{array}{l}\text { Mitogen/extracellular signal-regulated } \\
\text { kinase }\end{array}$ \\
\hline $\mathrm{MPP}^{+}:$ & 1-Methyl-4-phenylpyridinium \\
\hline MPTP: & $\begin{array}{l}\text { 1-Methyl-4-phenyl-1,2,3,6- } \\
\text { tetrahydropyridine }\end{array}$ \\
\hline MS: & Multiple sclerosis \\
\hline NADPH: & $\begin{array}{l}\text { Reduced form of nicotinamide adenine } \\
\text { dinucleotide phosphate }\end{array}$ \\
\hline NO: & Nitric oxide \\
\hline NMDA: & N-Methyl-D-aspartate \\
\hline ND: & Neurodegenerative diseases \\
\hline $\mathrm{NF}-\kappa \mathrm{B}:$ & Nuclear factor $-\kappa \mathrm{B}$ \\
\hline Nrf2: & Nuclear factor (erythroid-derived 2)-like 2 \\
\hline NOS: & Nitric oxide synthase \\
\hline 6-OHDA: & 6-Hydroxydopamine-intoxicated mice \\
\hline PC12: & $\begin{array}{l}\text { Cell line derived from a } \\
\text { pheochromocytoma of the rat adrenal } \\
\text { medulla }\end{array}$ \\
\hline PD: & Parkinson's disease \\
\hline PN: & Panax notoginseng \\
\hline ROS: & Reactive oxygen species \\
\hline SAC: & S-Allyl cysteine \\
\hline Sjh: & Sanmjuanhwan \\
\hline SCR: & Smilacis chinae rhizome \\
\hline SOD1: & Superoxide dismutase 1 \\
\hline TKT: & Toki To \\
\hline $\mathrm{TNF} \alpha$ & Tumor necrosis fa \\
\hline
\end{tabular}

\section{Conflict of Interests}

The authors declare that there is no conflict of interests regarding the publication of this paper.

\section{Authors' Contribution}

Jesús Pérez-Hernández and Víctor Javier Zaldívar-Machorro contributed equally to this paper.

\section{Acknowledgments}

Funding for this research was provided by the Medical School and grants from Dirección General de Asuntos del Personal Académico (DGAPA; IN217612 and IN222215), National Autonomous University of Mexico (UNAM). Jesús PérezHernández and David Villanueva-Porras are recipient of a fellowship sponsored by the Consejo Nacional de Ciencia y Tecnología (CONACyT) and Víctor Javier ZaldívarMachorro is recipient of a postdoctoral fellowship sponsored by DGAPA, UNAM.

\section{References}

[1] R. Fischer and O. Maier, "Interrelation of oxidative stress and inflammation in neurodegenerative disease: role of TNF," Oxidative Medicine and Cellular Longevity, vol. 2015, Article ID 610813, 18 pages, 2015.

[2] V. Procaccio, C. Bris, J. M. Chao de la Barca et al., "Perspectives of drug-based neuroprotection targeting mitochondria," Revue Neurologique, vol. 170, no. 5, pp. 390-400, 2014.

[3] M. Talarowska, K. Bobińska, M. Zajaczkowska, K.-P. Su, M. Maes, and P. Gałecki, "Impact of oxidative/nitrosative stress and inflammation on cognitive functions in patients with recurrent depressive disorders," Medical Science Monitor, vol. 20, pp. 110$115,2014$.

[4] C. Ballard, S. Gauthier, A. Corbett, C. Brayne, D. Aarsland, and E. Jones, “Alzheimer's disease," The Lancet, vol. 377, no. 9770, pp. 1019-1031, 2011.

[5] T. B. Joseph, S. W. J. Wang, X. Liu et al., "Disposition of flavonoids via enteric recycling: enzyme stability affects characterization of prunetin glucuronidation across species, organs, and UGT isoforms," Molecular Pharmaceutics, vol. 4, no. 6, pp. 883-894, 2007.

[6] S. Ramos, "Effects of dietary flavonoids on apoptotic pathways related to cancer chemoprevention," Journal of Nutritional Biochemistry, vol. 18, no. 7, pp. 427-442, 2007.

[7] G. Chiva-Blanch, M. Urpi-Sarda, R. Llorach et al., "Differential effects of polyphenols and alcohol of red wine on the expression of adhesion molecules and inflammatory cytokines related to atherosclerosis: a randomized clinical trial," The American Journal of Clinical Nutrition, vol. 95, no. 2, pp. 326-334, 2012.

[8] S. A. Rieder, P. Nagarkatti, and M. Nagarkatti, "Multiple antiinflammatory pathways triggered by resveratrol lead to amelioration of staphylococcal enterotoxin B-induced lung injury," British Journal of Pharmacology, vol. 167, no. 6, pp. 1244-1258, 2012.

[9] J. W. Gatson, M.-M. Liu, K. Abdelfattah et al., "Resveratrol decreases inflammation in the brain of mice with mild traumatic brain injury," Journal of Trauma and Acute Care Surgery, vol. 74, no. 2, pp. 470-475, 2013.

[10] C. A. Rice-Evans, N. J. Miller, and G. Paganga, "Structureantioxidant activity relationships of flavonoids and phenolic acids," Free Radical Biology and Medicine, vol. 20, no. 7, pp. 933956, 1996.

[11] P. Pignatelli, A. Ghiselli, B. Buchetti et al., "Polyphenols synergistically inhibit oxidative stress in subjects given red and white wine," Atherosclerosis, vol. 188, no. 1, pp. 77-83, 2006.

[12] B. Wright, L. A. Moraes, C. F. Kemp et al., "A structural basis for the inhibition of collagen-stimulated platelet function by quercetin and structurally related flavonoids," British Journal of Pharmacology, vol. 159, no. 6, pp. 1312-1325, 2010. 
[13] K. A. Jacobson, S. Moro, J. A. Manthey, P. L. West, and X.D. Ji, "Interactions of flavones and other phytochemicals with adenosine receptors," Advances in Experimental Medicine and Biology, vol. 505, pp. 163-171, 2002.

[14] B. Pawlikowska-Pawlega, W. Ignacy Gruszecki, L. Misiak et al., "Modification of membranes by quercetin, a naturally occurring flavonoid, via its incorporation in the polar head group," Biochimica et Biophysica Acta-Biomembranes, vol. 1768, no. 9, pp. 2195-2204, 2007.

[15] S.-Z. Zhong, Q.-H. Ge, R. Qu, Q. Li, and S.-P. Ma, "Paeonol attenuates neurotoxicity and ameliorates cognitive impairment induced by d-galactose in ICR mice," Journal of the Neurological Sciences, vol. 277, no. 1-2, pp. 58-64, 2009.

[16] J. K. Kim, H. Bae, M.-J. Kim et al., "Inhibitory effect of poncirus trifoliate on acetylcholinesterase and attenuating activity against trimethyltin-induced learning and memory impairment," Bioscience, Biotechnology and Biochemistry, vol. 73, no. 5, pp. 1105-1112, 2009.

[17] T. I. Kim, Y. K. Lee, S. G. Park et al., "l-Theanine, an amino acid in green tea, attenuates $\beta$-amyloid-induced cognitive dysfunction and neurotoxicity: reduction in oxidative damage and inactivation of ERK/p38 kinase and NF- $\kappa$ B pathways," Free Radical Biology and Medicine, vol. 47, no. 11, pp. 1601-1610, 2009.

[18] D. Y. Chuang, M.-H. Chan, Y. Zong et al., "Magnolia polyphenols attenuate oxidative and inflammatory responses in neurons and microglial cells," Journal of Neuroinflammation, vol. 10, article 15, 2013.

[19] K. Ono, Y. Yoshiike, A. Takashima, K. Hasegawa, H. Naiki, and M. Yamada, "Potent anti-amyloidogenic and fibril-destabilizing effects of polyphenols in vitro: implications for the prevention and therapeutics of Alzheimer's disease," Journal of Neurochemistry, vol. 87, no. 1, pp. 172-181, 2003.

[20] T. Sergent, N. Piront, J. Meurice, O. Toussaint, and Y.-J. Schneider, "Anti-inflammatory effects of dietary phenolic compounds in an in vitro model of inflamed human intestinal epithelium," Chemico-Biological Interactions, vol. 188, no. 3, pp. 659-667, 2010.

[21] J. R. Cannon and J. T. Greenamyre, "Neurotoxic in vivo models of Parkinson's disease: recent advances," in Progress in Brain Research, vol. 184, chapter 2, pp. 17-33, Elsevier, 2010.

[22] R. F. Haseloff, I. E. Blasig, H.-C. Bauer, and H. Bauer, "In search of the astrocytic factor(s) modulating blood-brain barrier functions in brain capillary endothelial cells in vitro," Cellular and Molecular Neurobiology, vol. 25, no. 1, pp. 25-39, 2005.

[23] B. V. Zlokovic, "The blood-brain barrier in health and chronic neurodegenerative disorders," Neuron, vol. 57, no. 2, pp. 178-201, 2008.

[24] K.-A. Hossmann, "Viability thresholds and the penumbra of focal ischemia," Annals of Neurology, vol. 36, no. 4, pp. 557-565, 1994.

[25] C. T. Drake and C. Iadecola, "The role of neuronal signaling in controlling cerebral blood flow," Brain and Language, vol. 102, no. 2, pp. 141-152, 2007.

[26] E. H. Lo, T. Dalkara, and M. A. Moskowitz, "Mechanisms, challenges and opportunities in stroke," Nature Reviews Neuroscience, vol. 4, no. 5, pp. 399-415, 2003.

[27] J. Lok, P. Gupta, S. Guo et al., "Cell-cell signaling in the neurovascular unit," Neurochemical Research, vol. 32, no. 12, pp. 2032-2045, 2007.

[28] T. R. Melzer, R. Watts, M. R. MacAskill et al., "Arterial spin labelling reveals an abnormal cerebral perfusion pattern in Parkinson's disease," Brain, vol. 134, no. 3, pp. 845-855, 2011.
[29] M. G. Spillantini, M. L. Schmidt, V. M.-Y. Lee, J. Q. Trojanowski, R. Jakes, and M. Goedert, "Alpha-synuclein in Lewy bodies," Nature, vol. 388, no. 6645, pp. 839-840, 1997.

[30] M. A. Burack, J. Hartlein, H. P. Flores, L. Taylor-Reinwald, J. S. Perlmutter, and N. J. Cairns, "In vivo amyloid imaging in autopsy-confirmed Parkinson disease with dementia," Neurology, vol. 74, no. 1, pp. 77-84, 2010.

[31] K. Iqbal and I. Grundke-Iqbal, "Alzheimer's disease, a multifactorial disorder seeking multitherapies," Alzheimer's and Dementia, vol. 6, no. 5, pp. 420-424, 2010.

[32] J. M. Anderson, D. W. Hampton, R. Patani et al., "Abnormally phosphorylated tau is associated with neuronal and axonal loss in experimental autoimmune encephalomyelitis and multiple sclerosis," Brain, vol. 131, no. 7, pp. 1736-1748, 2008.

[33] B. F. Shaw and J. S. Valentine, "How do ALS-associated mutations in superoxide dismutase 1 promote aggregation of the protein?" Trends in Biochemical Sciences, vol. 32, no. 2, pp. 7885, 2007.

[34] B. Uttara, A. V. Singh, P. Zamboni, and R. T. Mahajan, "Oxidative stress and neurodegenerative diseases: a review of upstream and downstream antioxidant therapeutic options," Current Neuropharmacology, vol. 7, no. 1, pp. 65-74, 2009.

[35] W. Dröge, "Free radicals in the physiological control of cell function," Physiological Reviews, vol. 82, no. 1, pp. 47-95, 2002.

[36] R. Von Bernhardi and J. Eugenín, “Alzheimer's disease: redox dysregulation as a common denominator for diverse pathogenic mechanisms," Antioxidants and Redox Signaling, vol. 16, no. 9, pp. 974-1031, 2012.

[37] B. Halliwell, "Oxidative stress and neurodegeneration: where are we now?" Journal of Neurochemistry, vol. 97, no. 6, pp. 1634$1658,2006$.

[38] A. Melo, L. Monteiro, R. M. F. Lima, D. M. de Oliveira, M. D. de Cerqueira, and R. S. El-Bachá, "Oxidative stress in neurodegenerative diseases: mechanisms and therapeutic perspectives," Oxidative Medicine and Cellular Longevity, vol. 2011, Article ID 467180, 14 pages, 2011.

[39] V. Chiurchiù and M. MacCarrone, "Chronic inflammatory disorders and their redox control: from molecular mechanisms to therapeutic opportunities," Antioxidants and Redox Signaling, vol. 15, no. 9, pp. 2605-2641, 2011.

[40] I.-T. Lee and C.-M. Yang, "Role of NADPH oxidase/ROS in pro-inflammatory mediators-induced airway and pulmonary diseases," Biochemical Pharmacology, vol. 84, no. 5, pp. 581-590, 2012.

[41] S. DiMauro and E. A. Schon, "Mitochondrial disorders in the nervous system," Annual Review of Neuroscience, vol. 31, pp. 91123, 2008.

[42] J. W. Lustbader, M. Cirilli, C. Lin et al., "ABAD directly links Abeta to mitochondrial toxicity in Alzheimer's disease," Science, vol. 304, no. 5669, pp. 448-452, 2004.

[43] C. Caspersen, N. Wang, J. Yao et al., "Mitochondrial A $\beta$ : a potential focal point for neuronal metabolic dysfunction in Alzheimer's disease," The FASEB Journal, vol. 19, no. 14, pp. 2040-2041, 2005.

[44] M. Manczak, T. S. Anekonda, E. Henson, B. S. Park, J. Quinn, and P. H. Reddy, "Mitochondria are a direct site of $\mathrm{A} \beta$ accumulation in Alzheimer's disease neurons: implications for free radical generation and oxidative damage in disease progression," Human Molecular Genetics, vol. 15, no. 9, pp. 14371449, 2006. 
[45] W. D. Parker Jr., S. J. Boyson, and J. K. Parks, "Abnormalities of the electron transport chain in idiopathic Parkinson's disease," Annals of Neurology, vol. 26, no. 6, pp. 719-723, 1989.

[46] P. Shi, J. Gal, D. M. Kwinter, X. Liu, and H. Zhu, "Mitochondrial dysfunction in amyotrophic lateral sclerosis," Biochimica et Biophysica Acta-Molecular Basis of Disease, vol. 1802, no. 1, pp. 45-51, 2010.

[47] W. J. Streit and C. A. Kincaid-Colton, "The brain's immune system," Scientific American, vol. 273, no. 5, pp. 54-61, 1995.

[48] Y. S. Kim and T. H. Joh, "Microglia, major player in the brain inflammation: their roles in the pathogenesis of Parkinson's disease," Experimental and Molecular Medicine, vol. 38, no. 4, pp. 333-347, 2006.

[49] E. G. McGeer and P. L. McGeer, "The role of anti-inflammatory agents in Parkinson's disease,” CNS Drugs, vol. 21, no. 10, pp. 789-797, 2007.

[50] P. Eikelenboom, C. Bate, W. A. Van Gool et al., "Neuroinflammation in Alzheimer's disease and prion disease," Glia, vol. 40, no. 2, pp. 232-239, 2002.

[51] P. Sanders and J. De Keyser, "Janus faces of microglia in multiple sclerosis," Brain Research Reviews, vol. 54, no. 2, pp. 274-285, 2007.

[52] R. M. Locksley, N. Killeen, and M. J. Lenardo, "The TNF and TNF receptor superfamilies: integrating mammalian biology," Cell, vol. 104, no. 4, pp. 487-501, 2001.

[53] R. E. Huie and S. Padmaja, "The reaction of no with superoxide," Free Radical Research, vol. 18, no. 4, pp. 195-199, 1993.

[54] E. Skrzydlewska, J. Ostrowska, R. Farbiszewski, and K. Michalak, "Protective effect of green tea against lipid peroxidation in the rat liver, blood serum and the brain," Phytomedicine, vol. 9, no. 3, pp. 232-238, 2002.

[55] T. Yokozawa, T. Nakagawa, and K. Kitani, "Antioxidative activity of green tea polyphenol in cholesterol-fed rats," Journal of Agricultural and Food Chemistry, vol. 50, no. 12, pp. 3549-3552, 2002.

[56] H. Negishi, J.-W. Xu, K. Ikeda, M. Njelekela, Y. Nara, and Y. Yamori, "Black and green tea polyphenols attenuate blood pressure increases in stroke-prone spontaneously hypertensive rats," Journal of Nutrition, vol. 134, no. 1, pp. 38-42, 2004.

[57] A. C. Mello-Filho and R. Meneghini, "Iron is the intracellular metal involved in the production of DNA damage by oxygen radicals," Mutation Research, vol. 251, no. 1, pp. 109-113, 1991.

[58] M. Bhattacharya, P. Ponka, P. Hardy et al., "Prevention of postasphyxia electroretinal dysfunction with a pyridoxal hydrazone," Free Radical Biology and Medicine, vol. 22, no. 1-2, pp. 11-16, 1997.

[59] Ling Dong Kong, C. H. K. Cheng, and Ren Xiang Tan, "Monoamine oxidase inhibitors from rhizoma of Coptis chinensis," Planta Medica, vol. 67, no. 1, pp. 74-76, 2001.

[60] E. D. Owuor and A.-N. T. Kong, "Antioxidants and oxidants regulated signal transduction pathways," Biochemical Pharmacology, vol. 64, no. 5-6, pp. 765-770, 2002.

[61] A. Scalbert, I. T. Johnson, and M. Saltmarsh, "Polyphenols: antioxidants and beyond," The American Journal of Clinical Nutrition, vol. 81, no. 1, supplement, pp. 215S-217S, 2005.

[62] T. Vuong, C. Matar, C. Ramassamy, and P. S. Haddad, "Biotransformed blueberry juice protects neurons from hydrogen peroxide-induced oxidative stress and mitogen-activated protein kinase pathway alterations," British Journal of Nutrition, vol. 104, no. 5, pp. 656-663, 2010.

[63] S. Asadi, A. Ahmadiani, M. A. Esmaeili, A. Sonboli, N. Ansari, and F. Khodagholi, "In vitro antioxidant activities and an investigation of neuroprotection by six Salvia species from Iran: a comparative study," Food and Chemical Toxicology, vol. 48, no. 5, pp. 1341-1349, 2010.

[64] C.-J. Wang, C.-P. Hu, K.-P. Xu et al., "Protective effect of selaginellin on glutamate-induced cytotoxicity and apoptosis in differentiated PC12 cells," Naunyn-Schmiedeberg's Archives of Pharmacology, vol. 381, no. 1, pp. 73-81, 2010.

[65] N. Mascolo, R. Jain, S. C. Jain, and F. Capasso, "Ethnopharmacologic investigation of ginger (Zingiber officinale)," Journal of Ethnopharmacology, vol. 27, no. 1-2, pp. 129-140, 1989.

[66] R. Grzanna, L. Lindmark, and C. G. Frondoza, "Gingeran herbal medicinal product with broad anti-inflammatory actions," Journal of Medicinal Food, vol. 8, no. 2, pp. 125-132, 2005.

[67] R. C. Lantz, G. J. Chen, M. Sarihan, A. M. Sólyom, S. D. Jolad, and B. N. Timmermann, "The effect of extracts from ginger rhizome on inflammatory mediator production," Phytomedicine, vol. 14, no. 2-3, pp. 123-128, 2007.

[68] Y. Masuda, H. Kikuzaki, M. Hisamoto, and N. Nakatani, "Antioxidant properties of gingerol related compounds from ginger," BioFactors, vol. 21, no. 1-4, pp. 293-296, 2004.

[69] H. W. Jung, H. Y. Son, C. Van Minn, Y. H. Kim, and Y.-K. Park, "Methanol extract of ficus leaf inhibits the production of nitric oxide and proinflammatory cytokines in LPS-stimulated microglia via the MAPK pathway," Phytotherapy Research, vol. 22, no. 8, pp. 1064-1069, 2008.

[70] H. W. Jung, C.-H. Yoon, K. M. Park, H. S. Han, and Y.-K. Park, "Hexane fraction of Zingiberis Rhizoma Crudus extract inhibits the production of nitric oxide and proinflammatory cytokines in LPS-stimulated BV2 microglial cells via the NFkappaB pathway," Food and Chemical Toxicology, vol. 47, no. 6, pp. 1190-1197, 2009.

[71] I. Häke, S. Schönenberger, J. Neuman et al., "Neuroprotection and enhanced neurogenesis by extract from the tropical plant Knema laurina after inflammatory damage in living brain tissue," Journal of Neuroimmunology, vol. 206, no. 1-2, pp. 91-99, 2009.

[72] D. Davalos, J. Grutzendler, G. Yang et al., "ATP mediates rapid microglial response to local brain injury in vivo," Nature Neuroscience, vol. 8, no. 6, pp. 752-758, 2005.

[73] L. Fetler and S. Amigorena, "Brain under surveillance: the microglia patrol," Science, vol. 309, no. 5733, pp. 392-393, 2005.

[74] J. Pérez-H, C. Carrillo-S, E. García, G. Ruiz-Mar, R. PérezTamayo, and A. Chavarría, "Neuroprotective effect of silymarin in a MPTP mouse model of Parkinson's disease," Toxicology, vol. 319, no. 1, pp. 38-43, 2014.

[75] D. Metodiewa and C. Kośka, "Reactive oxygen species and reactive nitrogen species: relevance to cyto(neuro)toxic events and neurologic disorders. An overview," Neurotoxicity Research, vol. 1, no. 3, pp. 197-233, 1999.

[76] G. E. Adamson, S. A. Lazarus, A. E. Mitchell et al., "HPLC method for the quantification of procyanidins in cocoa and chocolate samples and correlation to total antioxidant capacity," Journal of Agricultural and Food Chemistry, vol. 47, no. 10, pp. 4184-4188, 1999.

[77] J.-F. Bisson, A. Nejdi, P. Rozan, S. Hidalgo, R. Lalonde, and M. Messaoudi, "Effects of long-term administration of a cocoa polyphenolic extract (Acticoa powder) on cognitive performances in aged rats," British Journal of Nutrition, vol. 100, no. 1, pp. 94-101, 2008.

[78] N. Sangeetha, S. Aranganathan, and N. Nalini, "Silibinin ameliorates oxidative stress induced aberrant crypt foci and lipid 
peroxidation in 1,2 dimethylhydrazine induced rat colon cancer," Investigational New Drugs, vol. 28, no. 3, pp. 225-233, 2010.

[79] F. Galhardi, K. Mesquita, J. M. Monserrat, and D. M. Barros, "Effect of silymarin on biochemical parameters of oxidative stress in aged and young rat brain," Food and Chemical Toxicology, vol. 47, no. 10, pp. 2655-2660, 2009.

[80] M. Miyamoto, T. H. Murphy, R. L. Schnaar, and J. T. Coyle, "Antioxidants protect against glutamate-induced cytotoxicity in a neuronal cell line," Journal of Pharmacology and Experimental Therapeutics, vol. 250, no. 3, pp. 1132-1140, 1989.

[81] A.-H. A. Fayed, "Brain trace element concentration of rats treated with the plant alkaloid, Vincamine," Biological Trace Element Research, vol. 136, no. 3, pp. 314-319, 2010.

[82] N. Matsui, K. Takahashi, M. Takeichi et al., "Magnolol and honokiol prevent learning and memory impairment and cholinergic deficit in SAMP8 mice," Brain Research, vol. 1305, pp. 108117, 2009.

[83] N. C. Berchtold and C. W. Cotman, "Evolution in the conceptualization of dementia and Alzheimer's disease: Greco-Roman period to the 1960s," Neurobiology of Aging, vol. 19, no. 3, pp. 173-189, 1998.

[84] G. Perry, A. D. Cash, and M. A. Smith, "Alzheimer disease and oxidative stress," Journal of Biomedicine and Biotechnology, vol. 2, no. 3, pp. 120-123, 2002.

[85] S. Y. Kim, T. C. Moon, H. W. Chang, K. H. Son, S. S. Kang, and H. P. Kim, "Effects of tanshinone I isolated from Salvia miltiorrhiza Bunge on arachidonic acid metabolism and in vivo inflammatory responses," Phytotherapy Research, vol. 16, no. 7, pp. 616-620, 2002.

[86] E.-J. Park, Y.-Z. Zhao, Y.-C. Kim, and D. H. Sohn, "PF2401-SF, standardized fraction of Salvia miltiorrhiza and its constituents, tanshinone I, tanshinone IIA, and cryptotanshinone, protect primary cultured rat hepatocytes from bile acid-induced apoptosis by inhibiting JNK phosphorylation," Food and Chemical Toxicology, vol. 45, no. 10, pp. 1891-1898, 2007.

[87] D. H. Kim, S. J. Jeon, J. W. Jung et al., “Tanshinone congeners improve memory impairments induced by scopolamine on passive avoidance tasks in mice," European Journal of Pharmacology, vol. 574, no. 2-3, pp. 140-147, 2007.

[88] J. D. Adams, R. Wang, J. Yang, and E. J. Lien, "Preclinical and clinical examinations of Salvia miltiorrhiza and its tanshinones in ischemic conditions," Chinese Medicine, vol. 1, article 3, 2006.

[89] Z. Mei, F. Zhang, L. Tao et al., "Cryptotanshinone, a compound from Salvia miltiorrhiza modulates amyloid precursor protein metabolism and attenuates $\beta$-amyloid deposition through upregulating $\alpha$-secretase in vivo and in vitro," Neuroscience Letters, vol. 452, no. 2, pp. 90-95, 2009.

[90] N. Murata, K. Murakami, Y. Ozawa et al., "Silymarin attenuated the amyloid beta plaque burden and improved behavioral abnormalities in an Alzheimer's disease mouse model," Bioscience, Biotechnology and Biochemistry, vol. 74, no. 11, pp. 22992306, 2010.

[91] Y. K. Gupta, M. H. V. Kumar, and A. K. Srivastava, "Effect of Centella asiatica on pentylenetetrazole-induced kindling, cognition and oxidative stress in rats," Pharmacology Biochemistry and Behavior, vol. 74, no. 3, pp. 579-585, 2003.

[92] M. H. Veerendra Kumar and Y. K. Gupta, "Effect of different extracts of Centella asiatica on cognition and markers of oxidative stress in rats," Journal of Ethnopharmacology, vol. 79, no. 2, pp. 253-260, 2002.
[93] M. Dhanasekaran, L. A. Holcomb, A. R. Hitt et al., "Centella asiatica extract selectively decreases amyloid $\beta$ levels in hippocampus of Alzheimer's disease animal model," Phytotherapy Research, vol. 23, no. 1, pp. 14-19, 2009.

[94] J. Wang, L. Ho, W. Zhao et al., "Grape-derived polyphenolics prevent $\mathrm{A} \beta$ oligomerization and attenuate cognitive deterioration in a mouse model of Alzheimer's disease," Journal of Neuroscience, vol. 28, no. 25, pp. 6388-6392, 2008.

[95] A. Nakajima, T. Yamakuni, M. Haraguchi et al., "Nobiletin, a citrus flavonoid that improves memory impairment, rescues bulbectomy-induced cholinergic neurodegeneration in mice," Journal of Pharmacological Sciences, vol. 105, no. 1, pp. 122-126, 2007.

[96] H. Onozuka, A. Nakajima, K. Matsuzaki et al., "Nobiletin, a citrus flavonoid, improves memory impairment and $\mathrm{A} \beta$ pathology in a transgenic mouse model of Alzheimer's disease," Journal of Pharmacology and Experimental Therapeutics, vol.326, no. 3, pp. 739-744, 2008.

[97] H. Nagase, N. Omae, A. Omori et al., "Nobiletin and its related flavonoids with CRE-dependent transcription-stimulating and neuritegenic activities," Biochemical and Biophysical Research Communications, vol. 337, no. 4, pp. 1330-1336, 2005.

[98] K. Matsuzaki, Kenichi Miyazaki, S. Sakai et al., "Nobiletin, a citrus flavonoid with neurotrophic action, augments protein kinase A-mediated phosphorylation of the AMPA receptor subunit, GluR1, and the postsynaptic receptor response to glutamate in murine hippocampus," European Journal of Pharmacology, vol. 578, no. 2-3, pp. 194-200, 2008.

[99] H. A. Jung, B.-S. Min, T. Yokozawa, J.-H. Lee, Y. S. Kim, and J. S. Choi, "Anti-Alzheimer and antioxidant activities of coptidis rhizoma alkaloids," Biological and Pharmaceutical Bulletin, vol. 32, no. 8, pp. 1433-1438, 2009.

[100] D. K. Kim, K. T. Lee, N.-I. Baek et al., "Acetylcholinesterase inhibitors from the aerial parts of Corydalis speciosa," Archives of Pharmacal Research, vol. 27, no. 11, pp. 1127-1131, 2004.

[101] C. H. Park, S.-H. Kim, W. Choi et al., "Novel anticholinesterase and antiamnesic activities of dehydroevodiamine, a constituent of Evodia rutaecarpa," Planta Medica, vol. 62, no. 5, pp. 405-409, 1996.

[102] H. M. Shaheen, M.-T. Hsieh, B. H. Ali et al., "The ameliorating effects of the cognitive-enhancing Chinese herbs on scopolamine-induced amnesia in rats," Phytotherapy Research, vol. 14, no. 5, pp. 375-377, 2000.

[103] D. H. Kim, B. H. Yoon, Y. W. Kim et al., "The seed extract of Cassia obtusifolia ameliorates learning and memory impairments induced by scopolamine or transient cerebral hypoperfusion in mice," Journal of Pharmacological Sciences, vol. 105, no. 1, pp. 82-93, 2007.

[104] A. Fischer and I. Hanin, "Potential animal models for senile dementia of Alzheimer's type, with emphasis on AF64Ainduced cholinotoxicity," Annual Review of Pharmacology and Toxicology, vol. 26, pp. 161-181, 1986.

[105] P. Chonpathompikunlert, J. Wattanathorn, and S. Muchimapura, "Piperine, the main alkaloid of Thai black pepper, protects against neurodegeneration and cognitive impairment in animal model of cognitive deficit like condition of Alzheimer's disease," Food and Chemical Toxicology, vol. 48, no. 3, pp. 798-802, 2010.

[106] S. K. Gupta, P. Bansal, R. K. Bhardwaj, and T. Velpandian, "Comparative anti-nociceptive, anti-inflammatory and toxicity profile of nimesulide vs nimesulide and piperine combination," Pharmacological Research, vol. 41, no. 6, pp. 657-662, 2000. 
[107] M. H. Yang, K. D. Yoon, Y.-W. Chin et al., "Neuroprotective effects of Dioscorea opposita on scopolamine-induced memory impairment in in vivo behavioral tests and in vitro assays," Journal of Ethnopharmacology, vol. 121, no. 1, pp. 130-134, 2009.

[108] H. G. Kim, M. S. Ju, H. Park et al., "Evaluation of Samjunghwan, a traditional medicine, for neuroprotection against damage by amyloid-beta in rat cortical neurons," Journal of Ethnopharmacology, vol. 130, no. 3, pp. 625-630, 2010.

[109] C.-C. Hou, S.-J. Lin, J.-T. Cheng, and F.-L. Hsu, "Bacopaside III, bacopasaponin G, and bacopasides A, B, and C from Bacopa monniera," Journal of Natural Products, vol. 65, no. 12, pp. 17591763, 2002.

[110] M. Deepak, G. K. Sangli, P. C. Arun, and A. Amit, "Quantitative determination of the major saponin mixture bacoside $\mathrm{A}$ in Bacopa monnieri by HPLC," Phytochemical Analysis, vol. 16, no. 1, pp. 24-29, 2005.

[111] K. Sairam, M. Dorababu, R. K. Goel, and S. K. Bhattacharya, "Antidepressant activity of standardized extract of Bacopa monniera in experimental models of depression in rats," Phytomedicine, vol. 9, no. 3, pp. 207-211, 2002.

[112] S. Channa, A. Dar, S. Anjum, M. Yaqoob, and Atta-ur-Rahman, "Anti-inflammatory activity of Bacopa monniera in rodents," Journal of Ethnopharmacology, vol. 104, no. 1-2, pp. 286-289, 2006.

[113] P. K. Chaudhuri, R. Srivastava, S. Kumar, and S. Kumar, "Phytotoxic and antimicrobial constituents of Bacopa monnieri and Holmskioldia sanguinea," Phytotherapy Research, vol. 18, no. 2, pp. 114-117, 2004.

[114] N. Limpeanchob, S. Jaipan, S. Rattanakaruna, W. Phrompittayarat, and K. Ingkaninan, "Neuroprotective effect of Bacopa monnieri on beta-amyloid-induced cell death in primary cortical culture," Journal of Ethnopharmacology, vol. 120, no. 1, pp. 112-117, 2008.

[115] C. Stough, J. Lloyd, J. Clarke et al., "The chronic effects of an extract of Bacopa monniera (Brahmi) on cognitive function in healthy human subjects," Psychopharmacology, vol. 156, no. 4, pp. 481-484, 2001.

[116] A. Das, G. Shanker, C. Nath, R. Pal, S. Singh, and H. K. Singh, "A comparative study in rodents of standardized extracts of Bacopa monniera and Ginkgo biloba: anticholinesterase and cognitive enhancing activities," Pharmacology Biochemistry and Behavior, vol. 73, no. 4, pp. 893-900, 2002.

[117] S. Roodenrys, D. Booth, S. Bulzomi, A. Phipps, C. Micallef, and J. Smoker, "Chronic effects of Brahmi (Bacopa monnieri) on human memory," Neuropsychopharmacology, vol. 27, no. 2, pp. 279-281, 2002.

[118] F. Pérez-Severiano, R. Salvatierra-Sánchez, M. Rodríguez-Pérez et al., "S-Allylcysteine prevents amyloid-beta peptide-induced oxidative stress in rat hippocampus and ameliorates learning deficits," European Journal of Pharmacology, vol. 489, no. 3, pp. 197-202, 2004.

[119] H. Javed, M. M. Khan, A. Khan et al., "S-allyl cysteine attenuates oxidative stress associated cognitive impairment and neurodegeneration in mouse model of streptozotocin-induced experimental dementia of Alzheimer's type," Brain Research, vol. 1389, pp. 133-142, 2011.

[120] M. Philpott, K. S. Gould, C. Lim, and L. R. Ferguson, "In situ and in vitro antioxidant activity of sweetpotato anthocyanins," Journal of Agricultural and Food Chemistry, vol. 52, no. 6, pp. 1511-1513, 2004.

[121] L. E. Steed and V.-D. Truong, "Anthocyanin content, antioxidant activity, and selected physical properties of flowable purple-fleshed sweetpotato purees," Journal of Food Science, vol. 73, no. 5, pp. S215-S221, 2008.

[122] J. Ye, X. Meng, C. Yan, and C. Wang, "Effect of purple sweet potato anthocyanins on $\beta$-amyloid-mediated PC-12 cells death by inhibition of oxidative stress," Neurochemical Research, vol. 35, no. 3, pp. 357-365, 2010.

[123] J.-H. Heo, S.-T. Lee, K. Chu et al., "An open-label trial of Korean red ginseng as an adjuvant treatment for cognitive impairment in patients with Alzheimer's disease," European Journal of Neurology, vol. 15, no. 8, pp. 865-868, 2008.

[124] G. Fiskum, A. Starkov, B. M. Polster, and C. Chinopoulos, "Mitochondrial mechanisms of neural cell death and neuroprotective interventions in Parkinson's disease," Annals of the New York Academy of Sciences, vol. 991, pp. 111-119, 2003.

[125] Y. Levites, O. Weinreb, G. Maor, M. B. H. Youdim, and S. Mandel, "Green tea polyphenol (-)-epigallocatechin-3-gallate prevents $N$-methyl-4-phenyl-1,2,3,6-tetrahydropyridine-induced dopaminergic neurodegeneration," Journal of Neurochemistry, vol. 78, no. 5, pp. 1073-1082, 2001.

[126] J. Van Kampen, H. Robertson, T. Hagg, and R. Drobitch, "Neuroprotective actions of the ginseng extract G115 in two rodent models of Parkinson's disease," Experimental Neurology, vol. 184, no. 1, pp. 521-529, 2003.

[127] I. S. Kim, S. Koppula, P.-J. Park et al., "Chrysanthemum morifolium Ramat (CM) extract protects human neuroblastoma SH-SY5Y cells against MPP+-induced cytotoxicity," Journal of Ethnopharmacology, vol. 126, no. 3, pp. 447-454, 2009.

[128] X. Geng, X. Tian, P. Tu, and X. Pu, "Neuroprotective effects of echinacoside in the mouse MPTP model of Parkinson's disease," European Journal of Pharmacology, vol. 564, no. 1-3, pp. 66-74, 2007.

[129] M. Geed, D. Garabadu, A. Ahmad, and S. Krishnamurthy, "Silibinin pretreatment attenuates biochemical and behavioral changes induced by intrastriatal $\mathrm{MPP}^{+}$injection in rats," Pharmacology Biochemistry and Behavior, vol. 117, pp. 92-103, 2014.

[130] R. Haddadi, A. M. Nayebi, S. Farajniya, S. E. Brooshghalan, and H. Sharifi, "Silymarin improved 6-OHDA-induced motor impairment in hemi-parkisonian rats: behavioral and molecular study," DARU Journal of Pharmaceutical Sciences, vol. 22, no. 1, article 38, 2014.

[131] N. K. Singhal, G. Srivastava, D. K. Patel, S. K. Jain, and M. P. Singh, "Melatonin or silymarin reduces maneb- and paraquatinduced Parkinson's disease phenotype in the mouse," Journal of Pineal Research, vol. 50, no. 2, pp. 97-109, 2011.

[132] S. K. Abraham, N. Schupp, U. Schmid, and H. Stopper, "Antigenotoxic effects of the phytoestrogen pelargonidin chloride and the polyphenol chlorogenic acid," Molecular Nutrition and Food Research, vol. 51, no. 7, pp. 880-887, 2007.

[133] D. Vauzour, G. Ravaioli, K. Vafeiadou, A. Rodriguez-Mateos, C. Angeloni, and J. P. E. Spencer, "Peroxynitrite induced formation of the neurotoxins 5-S-cysteinyl-dopamine and DHBT-1: implications for Parkinson's disease and protection by polyphenols," Archives of Biochemistry and Biophysics, vol. 476, no. 2, pp. 145151, 2008.

[134] M. Roghani, A. Niknam, M.-R. Jalali-Nadoushan, Z. Kiasalari, M. Khalili, and T. Baluchnejadmojarad, "Oral pelargonidin exerts dose-dependent neuroprotection in 6-hydroxydopamine rat model of hemi-parkinsonism," Brain Research Bulletin, vol. 82, no. 5-6, pp. 279-283, 2010.

[135] E. Garcia, D. Limon, V. Perez-De La Cruz et al., "Lipid peroxidation, mitochondrial dysfunction and neurochemical and 
behavioural deficits in different neurotoxic models: protective role of S-allylcysteine," Free Radical Research, vol. 42, no. 10, pp. 892-902, 2008.

[136] E. García, J. Villeda-Hernández, J. Pedraza-Chaverrí, P. D. Maldonado, and A. Santamaría, "S-allylcysteine reduces the MPTPinduced striatal cell damage via inhibition of pro-inflammatory cytokine tumor necrosis factor- $\alpha$ and inducible nitric oxide synthase expressions in mice," Phytomedicine, vol. 18, no. 1, pp. 65-73, 2010.

[137] E. García, R. Santana-Martínez, C. A. Silva-Islas et al., "Sallyl cysteine protects against MPTP-induced striatal and nigral oxidative neurotoxicity in mice: participation of Nrf2," Free Radical Research, vol. 48, no. 2, pp. 159-167, 2014.

[138] D. V. G. de Andrade, D. M. de Oliveria, G. Barreto et al., "Effects of the extract of Anemopaegma mirandum (Catuaba) on Rotenone-induced apoptosis in human neuroblastomas SHSY5Y cells," Brain Research, vol. 1198, pp. 188-196, 2008.

[139] D. M. de Oliveria, G. Barreto, D. V. G. de Andrade et al., "Cytoprotective effect of valeriana officinalis extract on an in vitro experimental model of parkinson disease," Neurochemical Research, vol. 34, no. 2, pp. 215-220, 2009.

[140] K. Sapkota, S. Kim, S.-E. Park, and S.-J. Kim, "Detoxified extract of Rhus verniciflua stokes inhibits rotenone-induced apoptosis in human dopaminergic cells, SH-SY5Y," Cellular and Molecular Neurobiology, vol. 31, no. 2, pp. 213-223, 2011.

[141] B.-S. Choi, K. Sapkota, S. Kim, H. J. Lee, H.-S. Choi, and S.-J. Kim, "Antioxidant activity and protective effects of Tripterygium regelii extract on hydrogen peroxide-induced injury in human dopaminergic cells, SH-SY5Y,' Neurochemical Research, vol. 35, no. 8, pp. 1269-1280, 2010.

[142] H. An, I. S. Kim, S. Koppula et al., "Protective effects of Gastrodia elata Blume on MPP+-induced cytotoxicity in human dopaminergic SH-SY5Y cells," Journal of Ethnopharmacology, vol. 130, no. 2, pp. 290-298, 2010.

[143] S. S. Kang, J. Y. Lee, Y. K. Choi, G. S. Kim, and B. H. Han, "Neuroprotective effects of flavones on hydrogen peroxideinduced apoptosis in SH-SY5Y neuroblostoma cells," Bioorganic and Medicinal Chemistry Letters, vol. 14, no. 9, pp. 2261-2264, 2004.

[144] H.-Q. Chen, Z.-Y. Jin, X.-J. Wang, X.-M. Xu, L. Deng, and J.-W. Zhao, "Luteolin protects dopaminergic neurons from inflammation-induced injury through inhibition of microglial activation," Neuroscience Letters, vol. 448, no. 2, pp. 175-179, 2008.

[145] P. Wang, J. Kang, R. Zheng et al., "Scavenging effects of phenylpropanoid glycosides from Pedicularis on superoxide anion and hydroxyl radical by the spin trapping method(95)02255-4," Biochemical Pharmacology, vol. 51, no. 5, pp. 687-691, 1996.

[146] Y.-Y. Li, J.-H. Lu, Q. Li, Y.-Y. Zhao, and X.-P. Pu, "Pedicularioside A from Buddleia lindleyana inhibits cell death induced by 1-methyl-4-phenylpyridinium ions $\left(\mathrm{MPP}^{+}\right)$in primary cultures of rat mesencephalic neurons," European Journal of Pharmacology, vol. 579, no. 1-3, pp. 134-140, 2008.

[147] J. S. Shim, H. G. Kim, M. S. Ju, J. G. Choi, S. Y. Jeong, and M. S. Oh, "Effects of the hook of Uncaria rhynchophylla on neurotoxicity in the 6-hydroxydopamine model of Parkinson's disease," Journal of Ethnopharmacology, vol. 126, no. 2, pp. 361$365,2009$.

[148] H. V. Nobre-Júnior, R. A. Oliveira, F. D. Maia et al., "Neuroprotective effects of chalcones from Myracrodruon urundeuva on 6-hydroxydopamine-induced cytotoxicity in rat mesencephalic cells," Neurochemical Research, vol. 34, no. 6, pp. 1066-1075, 2009.

[149] Y. Wang, Y. Feng, Q. Fu, and L. Li, "Panax notoginsenoside Rbl ameliorates Alzheimer's disease by upregulating brainderived neurotrophic factor and downregulating Tau protein expression," Experimental and Therapeutic Medicine, vol. 6, no. 3, pp. 826-830, 2013.

[150] S. Y. Cheon, K. J. Cho, J. E. Lee et al., "Cerebroprotective effects of red ginseng extract pretreatment against ischemia-induced oxidative stress and apoptosis," International Journal of Neuroscience, vol. 123, no. 4, pp. 269-277, 2013.

[151] J. Bai, H. Nakamura, Y.-W. Kwon et al., "Critical roles of thioredoxin in nerve growth factor-mediated signal transduction and neurite outgrowth in PC12 cells," The Journal of Neuroscience, vol. 23, no. 2, pp. 503-509, 2003.

[152] F.-C. Luo, S.-D. Wang, K. Li, H. Nakamura, J. Yodoi, and J. Bai, "Panaxatriol saponins extracted from Panax notoginseng induces thioredoxin-1 and prevents 1-methyl-4-phenylpyridinium ion-induced neurotoxicity," Journal of Ethnopharmacology, vol. 127, no. 2, pp. 419-423, 2010.

[153] T. Kuboyama, C. Tohda, J. Zhao, N. Nakamura, M. Hattori, and K. Komatsu, "Axon- or dendrite-predominant outgrowth induced by constituents from Ashwagandha," NeuroReport, vol. 13, no. 14, pp. 1715-1720, 2002.

[154] C. Tohda, T. Kuboyama, and K. Komatsu, "Search for natural products related to regeneration of the neuronal network," NeuroSignals, vol. 14, no. 1-2, pp. 34-45, 2005.

[155] S. RajaSankar, T. Manivasagam, and S. Surendran, "Ashwagandha leaf extract: a potential agent in treating oxidative damage and physiological abnormalities seen in a mouse model of Parkinson's disease," Neuroscience Letters, vol. 454, no. 1, pp. $11-15,2009$.

[156] C.-M. Lin, R.-D. Lin, S.-T. Chen et al., "Neurocytoprotective effects of the bioactive constituents of Pueraria thomsonii in 6-hydroxydopamine (6-OHDA)-treated nerve growth factor (NGF)-differentiated PC12 cells," Phytochemistry, vol. 71, no. 1718, pp. 2147-2156, 2010.

[157] T. Baluchnejadmojarad, M. Roghani, M. R. J. Nadoushan, and M. Bagheri, "Neuroprotective effect of genistein in 6-hydroxydopamine hemi-parkinsonian rat model," Phytotherapy Research, vol. 23, no. 1, pp. 132-135, 2009.

[158] B. V. Manyam, M. Dhanasekaran, and T. A. Hare, "Neuroprotective effects of the antiparkinson drug Mucuna pruriens," Phytotherapy Research, vol. 18, no. 9, pp. 706-712, 2004.

[159] R. Sakai, Y. Irie, T. Murata, A. Ishige, N. Anjiki, and K. Watanabe, "Toki-to protects dopaminergic neurons in the substantia nigra from neurotoxicity of MPTP in mice," Phytotherapy Research, vol. 21, no. 9, pp. 868-873, 2007.

[160] Y. H. Choi, C. H. Yon, K. S. Hong et al., "In vitro BACE1 inhibitory phenolic components from the seeds of Psoralea corylifolia," Planta Medica, vol. 74, no. 11, pp. 1405-1408, 2008.

[161] G. Zhao, S.-Y. Zang, X.-W. Zheng, X.-H. Zhang, and L.-H. Guo, "Bakuchiol analogs inhibit monoamine transporters and regulate monoaminergic functions," Biochemical Pharmacology, vol. 75, no. 9, pp. 1835-1847, 2008.

[162] G. Zhao, X.-W. Zheng, G.-W. Qin, Y. Gai, Z.-H. Jiang, and L.-H. Guo, "In vitro dopaminergic neuroprotective and in vivo antiparkinsonian-like effects of $\Delta^{3}, 2$-hydroxybakuchiol isolated from Psoralea corylifolia (L.)," Cellular and Molecular Life Sciences, vol. 66, no. 9, pp. 1617-1629, 2009. 
[163] S. Cheung and J. Tai, "Anti-proliferative and antioxidant properties of rosemary Rosmarinus officinalis," Oncology Reports, vol. 17, no. 6, pp. 1525-1531, 2007.

[164] A.-H. Lo, Y.-C. Liang, S.-Y. Lin-Shiau, C.-T. Ho, and J.-K. Lin, "Carnosol, an antioxidant in rosemary, suppresses inducible nitric oxide synthase through down-regulating nuclear factor$\kappa \mathrm{B}$ in mouse macrophages," Carcinogenesis, vol. 23, no. 6, pp. 983-991, 2002.

[165] S.-J. Kim, J.-S. Kim, H.-S. Cho et al., "Carnosol, a component of rosemary (Rosmarinus officinalis L.) protects nigral dopaminergic neuronal cells," NeuroReport, vol. 17, no. 16, pp. 1729-1733, 2006.

[166] H. J. Lee, H.-S. Cho, E. Park et al., "Rosmarinic acid protects human dopaminergic neuronal cells against hydrogen peroxide-induced apoptosis," Toxicology, vol. 250, no. 2-3, pp. 109-115, 2008.

[167] J. A. Park, S. Kim, S.-Y. Lee et al., "Beneficial effects of carnosic acid on dieldrin-induced dopaminergic neuronal cell death," NeuroReport, vol. 19, no. 13, pp. 1301-1304, 2008.

[168] S. J. Posadas, V. Caz, C. Largo et al., "Protective effect of supercritical fluid rosemary extract, Rosmarinus officinalis, on antioxidants of major organs of aged rats," Experimental Gerontology, vol. 44, no. 6-7, pp. 383-389, 2009.

[169] S.-E. Park, S. Kim, K. Sapkota, and S.-J. Kim, "Neuroprotective effect of Rosmarinus officinalis extract on human dopaminergic cell line, SH-SY5Y," Cellular and Molecular Neurobiology, vol. 30, no. 5, pp. 759-767, 2010.

[170] X. Huang, Q. Li, Y. Zhang et al., "Neuroprotective effects of cactus polysaccharide on oxygen and glucose deprivation induced damage in rat brain slices," Cellular and Molecular Neurobiology, vol. 28, no. 4, pp. 559-568, 2008.

[171] X. Huang, Q. Li, H. Li, and L. Guo, "Neuroprotective and antioxidative effect of cactus polysaccharides in vivo and in vitro," Cellular and Molecular Neurobiology, vol. 29, no. 8, pp. 1211-1221, 2009.

[172] Y. B. Ju, O. C. Soon, S.-H. Choi et al., "Neuroprotective effect of Smilacis chinae rhizome on NMDA-induced neurotoxicity in vitro and focal cerebral ischemia in vivo," Journal of Pharmacological Sciences, vol. 106, no. 1, pp. 68-77, 2008.

[173] Y.-C. Hou, K.-T. Liou, C.-M. Chern et al., "Preventive effect of silymarin in cerebral ischemia-reperfusion-induced brain injury in rats possibly through impairing NF- $\kappa$ B and STAT-1 activation," Phytomedicine, vol. 17, no. 12, pp. 963-973, 2010.

[174] Y. Numagami, S. Sato, and S. T. Ohnishi, "Attenuation of rat ischemic brain damage by aged garlic extracts: a possible protecting mechanism as antioxidants," Neurochemistry International, vol. 29, no. 2, pp. 135-143, 1996.

[175] Y. Numagami and S. T. Ohnishi, "S-allylcysteine inhibits free radical production, lipid peroxidation and neuronal damage in rat brain ischemia," Journal of Nutrition, vol. 131, no. 3, pp. 1100S-1105S, 2001. 


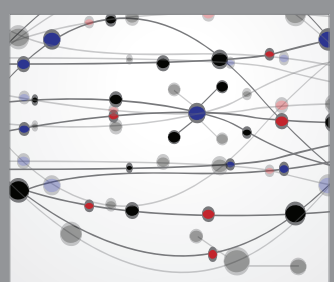

The Scientific World Journal
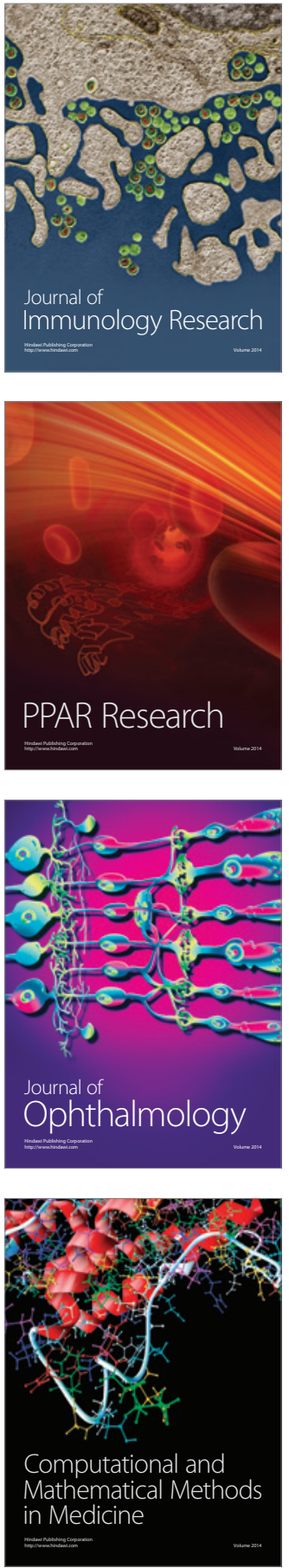

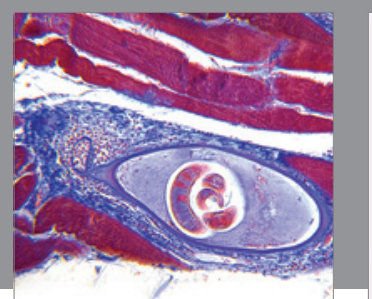

Gastroenterology Research and Practice

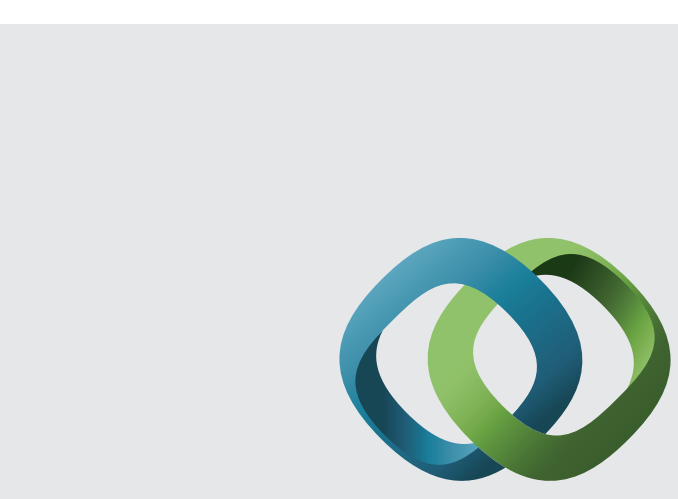

\section{Hindawi}

Submit your manuscripts at

http://www.hindawi.com
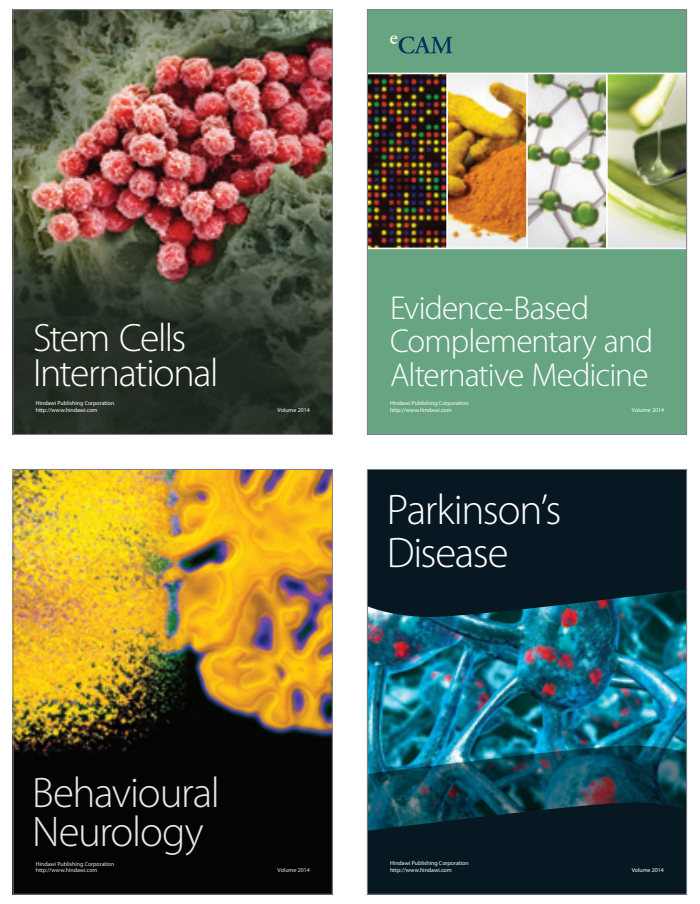
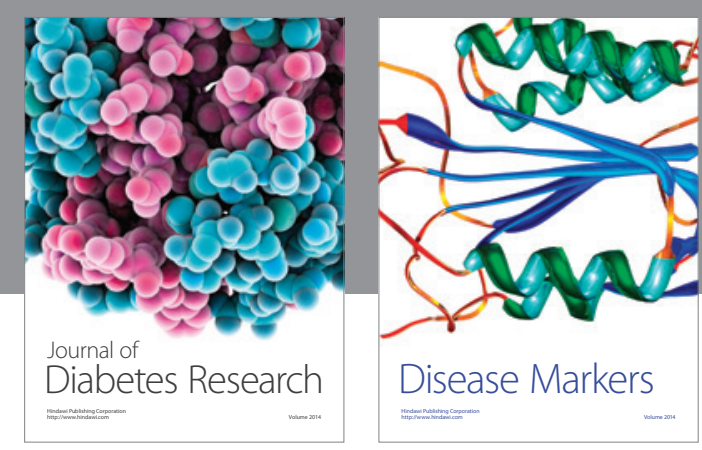

Disease Markers
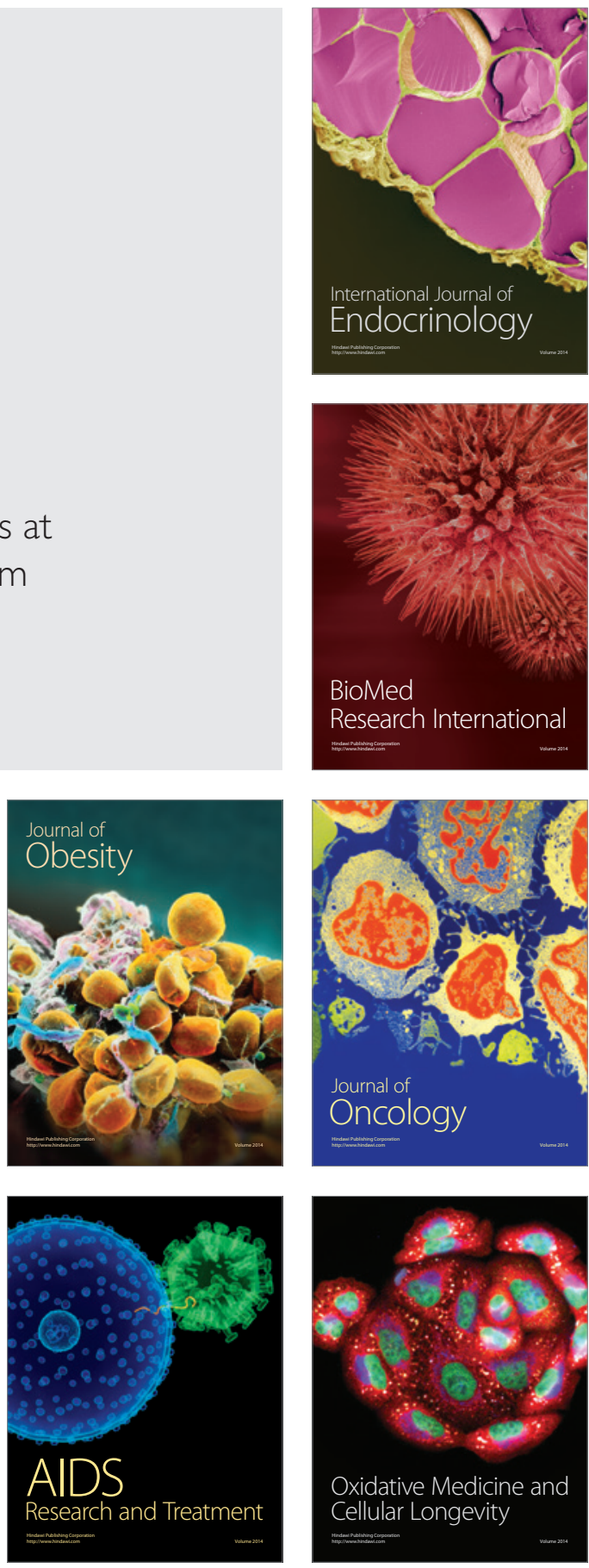